\title{
Role of nano-precipitation on the microstructure and shape memory characteristics of a new $\mathrm{Ni}_{50.3} \mathrm{Ti}_{34.7} \mathrm{Zr}_{15}$ shape memory alloy
}

\author{
A. Evirgen ${ }^{a}$, I. Karaman $^{a^{*}}$, J. Pons ${ }^{b}$, R. Santamarta ${ }^{\text {b }}$ R.D. Noebe ${ }^{c}$ \\ ${ }^{a}$ Department of Materials Science and Engineering, Texas A\&M University, College Station, TX 77843, USA \\ ${ }^{\mathrm{b}}$ Departament de Fisica, Universitat de les Illes Balears, E07122 Palma de Mallorca, Spain \\ ${ }^{c}$ Materials and Structures Division, NASA Glenn Research Center, Cleveland, OH 44135, USA \\ *: Corresponding Author, ikaraman@tamu.edu
}

\begin{abstract}
The microstructure and shape memory characteristics of the $\mathrm{Ni}_{50.3} \mathrm{Ti}_{34.7} Z \mathrm{Zr}_{15}$ shape memory alloy were investigated as a function of aging heat treatments that result in nanometer to submicron size precipitates. Microstructure-property relationships were developed by characterizing samples using transmission electron microscopy, differential scanning calorimetry, and load-biased thermal cycling experiments. The precipitate size was found to strongly influence the martensitic transformationprecipitate interactions and ultimately the shape memory characteristics of the alloy. Aging treatments resulting in relatively fine precipitates, which are not an obstacle to twin boundaries and easily bypassed by martensite variants, exhibited higher transformation strain, lower transformation thermal hysteresis, and better thermal and dimensional stability compared to samples with relatively large precipitates. When precipitate dimensions approached several hundred nanometers in size they acted as obstacles to martensite growth, limiting martensite variant and twin size resulting in reduced functional and structural properties. Aging heat treatments were also shown to result in a wide range of transformation temperatures, increasing them above $100{ }^{\circ} \mathrm{C}$ in some cases, and affected the stress dependence of the transformation hysteresis and the stress versus transformation temperature relationships for the $\mathrm{Ni}_{50.3} \mathrm{Ti}_{34.7} \mathrm{Zr}_{15}$ alloy.
\end{abstract}

Keywords: NiTiZr; Martensitic transformation; Precipitation; Microstructure; Shape memory alloys 


\section{Introduction}

Shape memory alloys (SMAs) are a unique group of functional materials that can recover their original shape after relatively large deformations by changes in temperature (shape memory effect) or stress (superelasticity) as a consequence of a reversible martensitic transformation (MT). NiTi is the most popular and commonly studied SMA system due to its many favorable functional and mechanical properties (e.g., ductility, workability, large transformation strains, corrosion resistance, high level of biocompatibility, etc.) Thus, it has been used in many medical and other applications such as actuators, couplings, valves, and switches [1-4].

However, commercially available NiTi SMAs have a few drawbacks hindering their use in applications that require high transformation temperatures and high strength because they generally undergo MT below $100^{\circ} \mathrm{C}$ and possess low strength against dislocation plasticity, which causes dimensional instability upon thermo-mechanical cycling $[3,5]$. Ternary alloying has long been used as a common method to overcome these limitations, improve the shape memory properties, and increase the transformation temperatures of binary NiTi alloys. Among the high-temperature NiTiX (X=Pt, Pd, Au, $\mathrm{Hf}, \mathrm{Zr}$ ) ternary SMA systems, NiTiHf and NiTiZr alloys have recently drawn increased attention due to their lower material cost as compared to NiTiPt/Pd/Au systems [6,7]. Furthermore, NiTiZr alloys provide an approximately $20 \%$ weight reduction compared to NiTiHf counterparts (i.e., NiTi-20Zr versus NiTi$20 \mathrm{Hf})$, have lower raw material costs, and are actually easier to process $[8,9]$.

Eckelmeyer [10] and Mulder [11] showed that the transformation temperatures of equatomic or Tirich binary NiTi SMAs can be increased by replacing Ti with Zr. It was reported that Zr additions above 10 at.\% result in an increase in the martensite start temperature $\left(\mathrm{M}_{\mathrm{s}}\right)$ at a rate of $18^{\circ} \mathrm{C} / \mathrm{at} . \% \mathrm{Zr}$ [6]. Hsieh et al. [12-14] studied the martensitic transformation behavior, lattice parameters of martensite, and the room temperature phases of (Ti+Zr)-rich NiTiZr alloys. Firstov et al. [15] investigated the high temperature shape memory behavior of (Ti+Zr)-rich NiTiZr alloys under compression. Although, these $(\mathrm{Ti}+\mathrm{Zr}$ )-rich NiTiZr alloys exhibit high transformation temperatures, they suffer from large thermal hysteresis and poor dimensional and thermal stability due to concurrent plasticity along with the transformation response, hampering their commercial use.

The transformation characteristics of NiTi-based SMAs can be modified through various matrix strengthening procedures such as cold working (i.e., cold rolling), precipitation hardening, or solidsolution alloying. However, cold rolling did not improve the shape memory response in the case of 
thermally cycled (Ti+Zr)-rich NiTiZr SMAs [16-18]. Microhardness values increased with thermal cycling and cold rolling, but martensite start $\left(M_{s}\right)$ temperatures decreased significantly $[16,18]$. Furthermore, microstructural control and stability is a big concern in the ( $\mathrm{Ti}+\mathrm{Zr}$ )-rich NiTiZr alloys since large (Ti,Zr) Ni, $(\mathrm{Ti}, \mathrm{Zr})_{2} \mathrm{Ni}$ and $\lambda_{1}$ (a NiTiZr ternary solid solution) second-phase particles were observed after conventional wrought alloy processing. These phases do not notably strengthen the matrix or improve the shape memory properties [14]. Solid-solution strengthening was also attempted, but again with little success. While $(\mathrm{Ti}+\mathrm{Zr} / \mathrm{Hf})$-rich NiTiZrHf quaternary alloys were reported to have higher annealed hardness values than their ternary NiTiZr counterparts, they exhibit higher transformation thermal hysteresis and similar shape recovery as compared to the ternary NiTiZr alloys [16].

On the contrary, Ni-rich compositions of binary NiTi SMAs can form metastable, nanosize $\mathrm{Ni}_{4} \mathrm{Ti}_{3}$ precipitates that significantly influence transformation temperatures, matrix strength, shape memory characteristics, and mechanical properties [19-27]. These fine precipitates increase the matrix strength and suppress extensive dislocation plasticity leading to improved dimensional stability upon thermomechanical loading and shape recovery. Additionally, transformation temperatures are altered as a result of the change in global matrix composition and local composition around the precipitates, as well as the coherency stress fields around the precipitates. All these effects are controlled by the size, volume fraction, and the interparticle spacing of the precipitates, which are a function of aging time and temperature.

Sandu and co-workers $[28,29]$ reported on the effects of aging on the microstructure, martensitic transformation temperatures, and mechanical behavior of Ni-rich NiTiZr SMAs, in particular $\mathrm{Ni}_{52} \mathrm{Ti}_{42} \mathrm{Zr}_{6}$ (at.\%). They determined that fine nanosize Ni-rich precipitates were present in the microstructure after certain heat treatments, which increased the hardness of the alloy. Although an increase in aging time was shown to increase the transformation temperatures, they were still significantly below $100^{\circ} \mathrm{C}$ since the $\mathrm{Zr}$ addition was just 6 at.\% with a very high initial Ni content. More recently, we have shown in a slightly Ni-rich NiTiZr SMA, i.e., $\mathrm{Ni}_{50.3} \mathrm{Ti}_{29.7} \mathrm{Zr}_{20}$, that precipitation hardening through the formation of nanosize precipitates results in excellent dimensional stability upon reversible MT without any need of thermo-mechanical training while also providing relatively high transformation temperatures [8]. The alloy also exhibits high strength, good superelasticity and excellent shape recovery at temperatures up to $250^{\circ} \mathrm{C}$ when nanosize precipitates $(<40 \mathrm{~nm})$ are present in the microstructure [9]. Except for these studies on Ni-rich NiTiZr SMAs with 6 at.\% and 20 at.\% Zr content, there has been no additional work carried out on Ni-rich NiTiZr SMAs, especially with Zr contents between these two concentrations. 
Considering the promising shape memory properties and excellent dimensional stability observed in Ni-rich $\mathrm{Ni}_{50.3} \mathrm{Ti}_{29.7} \mathrm{Zr}_{20}$, the present study was initiated to determine whether similar benefits could be developed in alloys with lower $\mathrm{Zr}$ content. Consequently, a $\mathrm{Ni}_{50.3} \mathrm{Ti}_{34.7} \mathrm{Zr}_{15} \mathrm{SMA}$ was systematically heat treated and characterized to understand the effects of aging on the microstructure and shape memory characteristics in the present study. Differential scanning calorimetry (DSC) was used to monitor the transformation temperatures of the alloy after systematic aging heat treatments and aging timetemperature-martensitic transformation temperature diagrams were generated. The shape memory and actuation response of the alloy was determined via load-biased thermo-mechanical cycling tests under constant stress in tension. These were combined with transmission electron microscopy (TEM) observations to reveal the effect of microstructure, in particular the precipitate size and martensite morphology, on the shape memory characteristics.

\section{Materials and Experimental Procedures}

A Ni-rich SMA with nominal composition of $\mathrm{Ni}_{50.3} \mathrm{Ti}_{34.7} \mathrm{Zr}_{15}$ (at. \%) was vacuum induction melted under a partial argon atmosphere using a graphite crucible and high purity elemental constituents of $\mathrm{Ni}$, $\mathrm{Ti}$ and $\mathrm{Hf}(99.98 \%, 99.95 \%$ and $99.9 \%$, respectively) and subsequently cast into a $25.4 \mathrm{~mm}$ diameter by $102 \mathrm{~mm}$ long copper mold with appropriate hot-top. The resulting ingot was homogenized at $1050{ }^{\circ} \mathrm{C}$ for 72 hours (hrs), sealed in a mild steel can, and then hot extruded at $900^{\circ} \mathrm{C}$ with an area reduction of 7:1.

Samples for DSC experiments, circular in shape with dimensions of $5 \mathrm{~mm}$ in diameter and $1 \mathrm{~mm}$ in thickness, and dog-bone shaped tensile samples for load-biased thermo-mechanical cycling, with 1.5 $\mathrm{mm} \times 3 \mathrm{~mm} \times 8 \mathrm{~mm}$ gage sections and tensile axis parallel to the extrusion direction, were cut from the extruded rod using wire electro-discharge machining (EDM). All the samples were first solution heat treated (SHT) at $900^{\circ} \mathrm{C}$ for 1 hour (h) in argon and subsequently water quenched (WQ) to assure a single phase structure before the precipitation heat treatments. Subsequently, the solution-treated samples were subjected to systematic isothermal aging treatments at temperatures from $450^{\circ} \mathrm{C}$ to $600^{\circ} \mathrm{C}$ for durations of $1 \mathrm{~h}$ to $200 \mathrm{~h}$ followed by water quenching in order to modify the precipitate structure and resulting transformation characteristics.

A TA Instruments, Q20 ${ }^{\mathrm{TM}}$ differential scanning calorimeter was used to measure the stress free transformation temperatures of the heat treated samples with a heating and cooling rate of $10^{\circ} \mathrm{C} \mathrm{min}^{-1}$. Three thermal cycles were conducted on each specimen between $-80^{\circ} \mathrm{C}$ and $200^{\circ} \mathrm{C}$ and the difference in $M_{s}$ temperatures between the first and third cycle $\left(M_{s 1}-M_{s 3}\right)$ was determined as a measure of the cyclic 
thermal stability of the transformation temperatures. Transformation thermal hysteresis values were measured as the difference between the first austenite finish $\left(A_{f}\right)$ and $M_{s}$ temperatures $\left(A_{f}-M_{s}\right)$.

On the basis of the DSC observations, samples showing relatively high transformation temperatures, low thermal hysteresis $(\Delta \mathrm{T})$, or good thermal stability were selected for load-biased thermal cycling experiments to investigate the effect of aging treatment on the shape memory response of the alloy. During these experiments, the samples were first loaded to a constant tensile stress in the fully austenitic state and thermally cycled between $-40^{\circ} \mathrm{C}$ and $200^{\circ} \mathrm{C}$. Upon completion of the thermal cycle, the stress was increased in $50 \mathrm{MPa}$ increments to the next level and the process was repeated until the specimens failed. A servo-hydraulic MTS test frame was used to conduct the thermo-mechanical cycling experiments. Specimens were heated and cooled through thermal conduction from the grips, which in turn were heated using resistive heating bands and cooled by flowing liquid nitrogen through copper tubing wrapped around the grips. The sample temperature during the experiment was measured using a K-type thermocouple attached directly to the gage section of the sample. The heating and cooling rate was $10^{\circ} \mathrm{C} \mathrm{min}{ }^{-1}$. The evolution of axial strain throughout the thermo-mechanical cycles was monitored using an MTS high-temperature extensometer mounted directly on the gage section of the specimen. The load-biased shape memory characteristics such as transformation temperatures, recovered transformation strain, unrecovered strain levels (an indication of dimensional instability), and thermal hysteresis were investigated as a function of applied stress through these experiments.

To analyze the initial microstructure and chemical composition of the solution heat treated $\mathrm{Ni}_{50.3} \mathrm{Ti}_{34.7} Z \mathrm{Zr}_{15}$ samples, specimens were prepared by mechanical polishing down to a final step of 0.05 $\mu \mathrm{m}$ colloidal silica and investigated using a Cameca SX-100 electron microprobe (EM) equipped with Xray energy dispersive spectrometry (EDS) and wavelength dispersive spectrometry (WDS) capabilities. Specimens for TEM analysis were prepared via mechanical grinding down to $100 \mu \mathrm{m}$ thickness followed by twin jet electropolishing using a $30 \% \mathrm{HNO}_{3}$ and $70 \%$ methanol solution at approximately $-20^{\circ} \mathrm{C}$. The resulting thin foils were investigated using a JEOL 2010 high resolution microscope with a LaB $_{6}$ filament operated at $200 \mathrm{kV}$ and equipped with an EDS detector. 


\section{Results and Discussion}

\subsection{Microstructure of $\mathrm{Ni}_{50.3} \mathrm{Ti}_{34.7} \mathrm{Zr}_{15}$}

Compositional analysis based on WDS measurements of the SHT sample, shown in Table 1, indicates $\sim 0.1$ at.\% Zr loss and a slight gain in Ni compared to the nominal alloy composition. The matrix was fully austenitic at room temperature with a grain size ranging from $25 \mu \mathrm{m}$ to $100 \mu \mathrm{m}$ as seen in the backscattered electron (BSE) image shown in Fig. 1. The composition is quite uniform in the matrix as shown by the very small variation in the measured compositions in Table 1. No secondary phases were visible except heterogeneously distributed white particles $(<3 \mu \mathrm{m}$ in size), which were found to be zirconium carbide via EDS. The zirconium carbide particles were formed during vacuum induction melting of the alloy due to reaction with the graphite crucible, in turn, decreasing the $\mathrm{Zr}$ content of the SHT matrix as demonstrated by the WDS investigation.

The transformation temperatures, thermal hysteresis, and thermal stability of all aged samples were investigated via DSC and these results will be discussed in detail below. The microstructures of those samples that showed relatively low thermal hysteresis (sample aged at $500{ }^{\circ} \mathrm{C}$ for $200 \mathrm{~h}$, referred to as

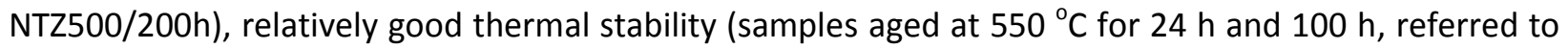
as NTZ550/24h and NTZ550/100h, respectively) and relatively high transformation temperatures (sample aged at $600{ }^{\circ} \mathrm{C}$ for $100 \mathrm{~h}$, referred to as NTZ600/100h) were further investigated using TEM. Bright field TEM and high resolution bright field TEM (HRTEM) images of these $\mathrm{Ni}_{50.3} \mathrm{Ti}_{34.7} \mathrm{Zr}_{15}$ samples are shown in Fig. 2.

A dense distribution of spindle like precipitates, $20-70 \mathrm{~nm}$ in length and 10-16 nm in width, embedded in a fully austenitic matrix at room temperature, were present after aging at $500^{\circ} \mathrm{C}$ for $200 \mathrm{~h}$ (Fig. 2a). At higher resolution (Fig. 2b), the precipitates show a perfect continuity of atomic planes at the austenite (B2) - precipitate boundary (inset image of Fig. 2b), which is consistent with previous TEM observations on the same alloy that indicate a coherent precipitate phase [31]. When the samples were aged at higher temperatures, such as $550^{\circ} \mathrm{C}$ or $600^{\circ} \mathrm{C}$, the specimens exhibited higher transformation temperatures and consequently the matrix was mostly a monoclinic (B19') martensite phase at room temperature (Figs. $2 \mathrm{c}$ to $\mathrm{f}$ ).

After aging for $24 \mathrm{~h}$ at $550^{\circ} \mathrm{C}$, the precipitates remained spindle shaped with sizes around $30-90 \mathrm{~nm}$ in length and $10-20 \mathrm{~nm}$ in width (Fig. 2c). In this condition, the precipitate size was sufficiently small so 
that the strain fields around the precipitates upon the forward transformation were accommodated by the growing martensite variants, and hence, the precipitates were easily absorbed by the propagating martensite plates, as seen in Fig. 2c. In other words, the precipitates do not stop the martensite interface motion and thus, a single martensite variant consists of large number of precipitates in them.

Precipitates coarsen upon further aging at $550^{\circ} \mathrm{C}$ for $100 \mathrm{~h}$, and reach a size of 75-160 nm in length and 15-30 nm in width (Fig. 2d). However, martensite plates can still absorb the precipitates upon transformation. Even at this size, the precipitate was not large enough to sufficiently interfere with the forward transformation or change the martensite morphology. Moreover, a good continuity of the atomic planes with a small amount of tilt was still visible across the interface (a white line parallel to these atomic planes was drawn to indicate the continuity) as shown in the HRTEM image (Fig. 2e) taken from the precipitate (P) - martensite (M) boundary in NTZ550/100h sample. The fast fourier transform (FFT) images belonging to the B19' martensite matrix and the precipitate phase were also included as insets and labeled with letter " $\mathrm{M}$ " and " $\mathrm{P}$ ", respectively. For the specific martensite variant shown in Fig. 2e, the change in the interplanar distance with $\mathrm{MT}$ is small and the atomic planes across the matrix/precipitate interface can maintain good continuity and hence coherency. However, although it was not observed in the NTZ550/24h and NTZ550/100h samples, larger changes in interplanar distances may happen leading to a remarkable loss of the coherency between the non-deforming precipitates and the martensite matrix for some other martensite variants. Such observations were reported for other Ni-rich NiTiHf and NiTiZr alloys in which large distortions of atomic planes were seen at the interface between martensite and precipitates leading to misfit dislocations [30].

The exact mechanism of how the martensite plates absorb the precipitates is not yet known, however there are several parameters, such as crystallography of both phases, their lattice mismatch, relative stiffnesses, and the amount of martensitic transformation strain, that influence the process. As a consequence, the effect of precipitates on martensitic transformation seen in different SMA systems can be quite different. Therefore, further research including detailed TEM investigations and molecular dynamics simulations should be performed to clarify the mechanisms governing the interaction process between martensite growth and precipitates.

Significant coarsening of the precipitates was observed after aging at $600{ }^{\circ} \mathrm{C}$ for $100 \mathrm{~h}$ (Fig. 2f), reaching several hundred nanometers in size (150-450 $\mathrm{nm}$ in length and 25-90 $\mathrm{nm}$ in width). At this size the precipitates act as impenetrable obstacles for the martensite variants. These large precipitates, which are indicated with white arrows in Fig. $2 f$, clearly interfere with the martensite propagation and 
have a strong influence on the martensite morphology and microstructure. Fig. $2 f$ shows that the martensite formation was constrained between precipitates and consisted of fine internal twins in order to accommodate the transformation shear and incompatibility between austenite and martensite phases while being constrained between the large precipitates. Similar effects of precipitate size on the martensite morphology were also reported for Ni-rich binary NiTi [24, 25, 31] and ternary NiTiHf [32] and NiTiZr [8, 9] alloys as well as several other SMA systems such as CuZnAl [33, 34] and CoNiGa [35] alloys.

The precipitate phase in the present $\mathrm{Ni}_{50.3} \mathrm{Ti}_{34.7} Z \mathrm{Zr}_{15}$ SMA had the same crystal structure as the precipitates identified recently in other Ni-rich NiTiHf and NiTiZr alloys. The selected area diffraction pattern (SADP), in Fig. 2g, (taken along the [001 $]_{\mathrm{B} 2}$ zone axis), shows two variants of precipitates simultaneously with $1 / 3<110>$ satellite spots (red arrows) and another two variants with $1 / 4<210>$ satellites (blue arrows), which are typical for the so-called H-phase. Details on the crystallographic properties and the structure of the H-phase precipitates were previously reported by Yang et al. [36] and Santamarta et al. [30].

It is worth nothing that the $\mathrm{ZrC}$ particles, initially formed in the microstructure (Fig. 1) due to the use of graphite crucibles during alloy melting, exhibit a much larger particle size and interparticle distance which is orders of magnitude larger than the interparticle distance between even the largest H-phase precipitates formed after aging at $600{ }^{\circ} \mathrm{C}$ for $100 \mathrm{~h}$ thermal treatment (Fig. 2f). Therefore, the effect of $\mathrm{ZrC}$ particles on the martensite microstructure is expected to be insignificant as compared to the $\mathrm{H}$ phase precipitation.

\subsection{Transformation temperatures and characteristics}

No martensitic transformation (MT) was detected in the DSC thermograms recorded down to $-80^{\circ} \mathrm{C}$ for the SHT sample and for the samples aged at $450^{\circ} \mathrm{C}$, even for aging times as long as $200 \mathrm{~h}$. Furthermore, the transformation temperatures were still below $-80^{\circ} \mathrm{C}$ during the initial stages of aging at $500^{\circ} \mathrm{C}$ (i.e., $1 \mathrm{~h}$ and $3 \mathrm{~h}$ aging), and the MT peaks were visible only after $10 \mathrm{~h}$ or longer aging at $500^{\circ} \mathrm{C}$. All the aged samples showed single step transformation behavior during forward and reverse MT from B2 austenite to B19' martensite or vice-versa. As seen from the representative DSC curves for the samples aged at $550{ }^{\circ} \mathrm{C}$ (Fig. 3), no multiple step or R-phase peaks were observed contrary to the observations of Javadi et al. [37] and Meng et al. [38-40] on several Ni-rich NiTiHf alloys, which have the same type of precipitates $[30,36]$. The multi-step transformations in these studies were generally attributed to 
heterogeneous distribution of the nanosize precipitates. However, the single step transformations seen in the present samples are in accordance with the microstructures shown in Fig. 2, which consist of homogeneously distributed $\mathrm{H}$-phase precipitates in the matrix. The present observations of a single stage martensitic transformation are also consistent with other studies on Ni-rich NiTiHf alloys of similar composition [32, 41] and other Ni-rich NiTiZr alloys [8, 9].

A summary of the $A_{f}$ and $M_{s}$ temperatures obtained in the $\mathrm{Ni}_{50.3} \mathrm{Ti}_{34.7} \mathrm{Zr}_{15}$ samples aged at $500{ }^{\circ} \mathrm{C}, 550$ ${ }^{\circ} \mathrm{C}$ and $600{ }^{\circ} \mathrm{C}$ for various durations is presented in Figs. $4 \mathrm{a}$ and $4 \mathrm{~b}$, respectively. As seen in these figures, the transformation temperatures for $\mathrm{Ni}_{50.3} \mathrm{Ti}_{34.7} Z \mathrm{Zr}_{15}$ occur over a large range: from $40{ }^{\circ} \mathrm{C}$ to $140{ }^{\circ} \mathrm{C}$ for $\mathrm{A}_{f}$ and from $-20^{\circ} \mathrm{C}$ to $80^{\circ} \mathrm{C}$ for $\mathrm{M}_{\mathrm{s}}$. This $100^{\circ} \mathrm{C}$ temperature window is as a consequence of the different precipitate volume fractions formed during aging. Transformation temperatures of the samples aged at $550{ }^{\circ} \mathrm{C}$ and $600{ }^{\circ} \mathrm{C}$ increased rapidly during the initial stages of aging, i.e., up to $24 \mathrm{~h}$ of aging, and then more gradually with further aging up to $200 \mathrm{~h}$. In contrast, the transformation temperatures for samples aged at $500{ }^{\circ} \mathrm{C}$ only increased after $48 \mathrm{~h}$ aging and were essentially constant from $10 \mathrm{~h}$ to $48 \mathrm{~h}$ aging (the changes of $\pm 3^{\circ} \mathrm{C}$ lie within the error of the DSC method).

Previous studies on binary Ni-rich NiTi [21] and Ni-rich NiTiHf alloys [32, 41] showed that the MT temperatures decrease during the initial stages of low temperature aging. This was attributed to difficulties in nucleation of martensite caused by a high density of very fine nanometric precipitates, resulting in an interparticle spacing that is similar or smaller than the critical size for martensite nucleation, thus requiring additional undercooling to form. This initial decrease in $M_{s}$ at low aging temperatures is generally followed by an increase when aging temperatures or times are increased. At higher aging temperatures or times, the precipitates coarsen resulting in larger interparticle distances. Thus, martensite nucleation is less inhibited by the precipitates and the MT temperatures increase because of the resulting compositional change of the matrix. An increasing volume fraction of Ni-rich precipitates (as in this case [30]) results in a matrix composition that is less Ni-rich and closer to stoichiometry, resulting in an increase in transformation temperatures.

The transformation temperatures of the present $\mathrm{Ni}_{50.3} \mathrm{Ti}_{34.7} \mathrm{Zr}_{15} \mathrm{SMA}$ in the SHT condition and aged samples at $400{ }^{\circ} \mathrm{C}$ and $450^{\circ} \mathrm{C}$ up to $200 \mathrm{~h}$ are below the DSC detection limit. Higher aging temperatures are needed to create sufficient precipitate volume fraction and matrix composition change to raise the transformation temperatures to the level accessible by the existing DSC. At $550{ }^{\circ} \mathrm{C}$ and $600{ }^{\circ} \mathrm{C}$, the matrix composition changes quite rapidly during the first few hours of aging (up to $24 \mathrm{~h}$ ) and, therefore, transformation temperatures increase more dramatically with initial aging time. The transformation 
temperatures continue to increase gradually with further aging at these temperatures until the increase becomes nearly insignificant after $100 \mathrm{~h}\left(\sim 4{ }^{\circ} \mathrm{C}\right.$ increase at $550{ }^{\circ} \mathrm{C}$ and $7{ }^{\circ} \mathrm{C}$ increase at $600{ }^{\circ} \mathrm{C}$ between the $100 \mathrm{~h}$ and $200 \mathrm{~h}$ heat treatments) as the equilibrium volume fraction of precipitate phase is reached. The volume fraction of precipitate phase is barely high enough to raise the transformation temperatures over $-80{ }^{\circ} \mathrm{C}$ after aging at $500{ }^{\circ} \mathrm{C}$ for $10 \mathrm{~h}$, though the MT temperatures show a considerable increase after more than $48 \mathrm{~h}$ of aging.

As seen in Fig. 3, three stress free DSC cycles were carried out on each sample in order to assess the thermal stability of the transformation temperatures. Fig. 5a shows the shift in $M_{s}$ temperatures as indicated by the difference between the first and the third DSC cycles $\left(M_{s 1}-M_{s 3}\right)$. The change in $M_{s}$ during thermal cycling is a measure of thermal stability, thus a material showing negligible or no change in $\mathrm{M}_{\mathrm{s}}$ is assumed to be "thermally stable". The change in transformation temperatures with stress free thermal cycling has been generally attributed to defect generation during the repetitive motion of the transformation interface and the accommodation of the transformation shape change through the formation of dislocations and other defects at the austenite-martensite interface [3]. Although there is no clear trend in the amount of shift in the $M_{s}$ temperatures as a consequence of thermal cycling in samples aged for a few tens of hours, the difference tends to reach a plateau after $48 \mathrm{~h}$ of aging and does not change significantly thereafter. The smallest temperature changes are obtained after aging at $500^{\circ} \mathrm{C}$ (around $4-5^{\circ} \mathrm{C}$ shift in transformation temperature), while the largest differences are observed in the samples aged at $600^{\circ} \mathrm{C}\left(>10^{\circ} \mathrm{C}\right)$. This is due to differences in precipitate size and interparticle distances for samples aged at different temperatures. The matrix hardening is more efficient due to the presence of smaller precipitates and their denser distribution after low temperature aging. But in general, the thermal stability of the present $\mathrm{Ni}_{50.3} \mathrm{Ti}_{34.7} \mathrm{Zr}_{15} \mathrm{SMA}$ is worse than the Ni-rich NiTiHf alloy with a similar composition $\left(\mathrm{Ni}_{50.3} \mathrm{Ti}_{34.7} \mathrm{Hf}_{15}\right)[32,41]$.The reason for this difference is not clear, but it could be due to better lattice compatibility between the austenite and martensite phases in NiTiHf alloys than that in NiTiZr alloys with similar stoichiometries.

Fig. $5 \mathrm{~b}$ represents the thermal hysteresis values of the aged $\mathrm{Ni}_{50.3} \mathrm{Ti}_{34.7} \mathrm{Zr}_{15}$ samples determined as the difference between the $A_{f}$ and $M_{s}$ temperatures $\left(A_{f}-M_{s}\right)$ of the first DSC cycle. The thermal hysteresis values vary between $53^{\circ} \mathrm{C}$ and $66^{\circ} \mathrm{C}$ and are comparable to the thermal hysteresis measured in the aged $\mathrm{Ni}_{50.3} \mathrm{Ti}_{34.7} \mathrm{Hf}_{15}$ alloy $[32,41]$. Although there is no clear relationship between the aging time and thermal hysteresis, it is obvious that the thermal hysteresis values generally decrease up to $24 \mathrm{~h}$ of aging, then follow almost a stable behavior up to $200 \mathrm{~h}$ (slight fluctuations are in the range of error in 
the DSC experiments) (Fig. 5b). In SMAs, the increase in matrix strength due to precipitation hardening generally decreases the energy dissipation during the transformation, and hence, the thermal hysteresis also decreases. Therefore, at fixed aging temperatures, the initial increase in precipitate volume fraction with aging time increases matrix strength, and thus, decreases thermal hysteresis. However, once the precipitate volume fraction saturates as in aging times longer than $48 \mathrm{~h}$, there is no further increase in the matrix strength and the transformation hysteresis stabilizes and may even begin to increase as the precipitates coarsen and spacing between the precipitates increases. With an increase in aging temperature, the thermal hysteresis values also increase. This is again due to the larger precipitate sizes obtained at higher aging temperatures as well as a smaller volume fraction of precipitate phase as the aging temperatures approach the solvus temperature of the alloy, and hence, result in a lower matrix strength. Moreover, when the precipitates are several hundreds of nanometers in size and cannot be absorbed by the martensite variants during transformation, the number of intervariant boundaries and their interaction increases (Fig. 2d). This could also contribute to the increase in thermal hysteresis observed for longer aging times at 550 and $600^{\circ} \mathrm{C}$.

The data derived from the DSC measurements $\left(A_{f}\right.$ and $M_{s}$ in Figs. $4 a$ and $4 b$, respectively), were replotted to generate the aging time-temperature-martensitic transformation temperature diagrams for the $A_{f}$ and $M_{s}$ temperatures of the $\mathrm{Ni}_{50.3} \mathrm{Ti}_{34.7} \mathrm{Zr}_{15}$ alloy shown in Figs. 6a and $6 \mathrm{~b}$, respectively. These diagrams are useful for the selection of processing parameters for a particular alloy such as $\mathrm{Ni}_{50.3} \mathrm{Ti}_{34.7} \mathrm{Zr} \mathrm{r}_{15}$, which generate desired transformation temperatures for a given application. The aging times are converted to minutes and the horizontal axis of the diagrams is presented in logarithmic scale to clearly identify trends in the transformation temperatures as a function of aging time and temperature. Each curve in the diagrams represents the loci of a constant $A_{f}$ or $M_{s}$. As seen in Figs. 6a and $6 \mathrm{~b}$, the transformation temperatures always increase with an increase in aging time for a fixed aging temperature (i.e., negative slope of the constant transformation temperature curves with time) in accordance with the trends seen in Fig. 4. Similarly, the transformation temperatures consistently increase with an increase in aging temperature at fixed aging times. No transformation peak was recorded for short aging durations at aging temperatures below $550^{\circ} \mathrm{C}$ (i.e., $1 \mathrm{~h}$ or $3 \mathrm{~h}$ at $500^{\circ} \mathrm{C}$ ) as indicated in the bottom left part of the diagrams (grey shaded area).

\subsection{Load-biased Shape Memory Response}

The shape memory response of the $\mathrm{Ni}_{50.3} \mathrm{Ti}_{34.7} \mathrm{Zr}_{15}$ alloy was studied via load-biased thermal cycling tests in tension. The experiments were carried out on those samples that exhibited good thermal 
stability (NTZ550/24h and NTZ550/100h), relatively low thermal hysteresis (NTZ500/200h), and relatively high transformation temperatures (NTZ600/100h). The strain vs. temperature responses of all four sample conditions under various applied stress levels are presented in Figs. 7a-7d. Critical shape memory characteristics such as transformation temperatures, thermal hysteresis, recovered transformation and unrecovered strain levels were determined as a function of applied stress by analyzing each thermal cycle as demonstrated in Fig. 7e.

Samples NTZ550/24h and NTZ600/100h were also selected in order to compare the effect of significantly different microstructures (Fig. 2) on the thermo-mechanical response of the alloy. In the NTZ550/24h sample, the precipitates were smaller than $90 \mathrm{~nm}$ and were absorbed by the martensite plates. In this case (Fig. 7b), perfect shape recovery, (i.e., no unrecovered strains upon heating to austenite), was observed even at $300 \mathrm{MPa}$ applied stress, due to the increased matrix strength. Similar load-biased thermo-mechanical responses were obtained for the NTZ500/200h and NTZ550/100h samples (Figs. 7a and 7c). On the other hand, the NTZ600/100h sample contained large precipitates (>100 nm, Fig. 2f) that limited the growth of martensite variants. This sample exhibited small unrecovered strains under $200 \mathrm{MPa}$ and $250 \mathrm{MPa}$ stress levels and failed at stresses above $250 \mathrm{MPa}$. This notably different behavior of the NTZ600/100h sample is due to the presence of large precipitates that significantly alter the martensite morphology. These large particles strongly interfere with the growth of martensite variants as well as reorientation or detwinning of martensite.

All the samples mentioned above showed failure when they were tested at stress levels of $250 \mathrm{MPa}$ and above. Independent of the precipitate size or martensite microstructure, the cracks leading to somewhat premature failure should initiate at surface asperities or the largest defects in the microstructure, which are the micron size $\mathrm{ZrC}$ particles in both cases above. The precipitates much smaller than $\mathrm{ZrC}$ particles would not be the major factor for the initiation of cracks in the presence of the large ZrC particles. However, all the samples with fine precipitates and large variants (NTZ500/200h, NTZ550/24h and NTZ550/100h) showed failure when they were tested at stress levels higher than 300 MPa, while the samples with large precipitates and fine martensite variants and twins showed premature failure at lower stress levels. NTZ600/100h samples always failed when they were tested at stress levels $250 \mathrm{MPa}$ and higher. These observations clearly indicate that the samples with large precipitates are consistently more brittle than the samples with fine precipitates. Therefore, these precipitates most likely control the crack propagation while $\mathrm{ZrC}$ particles control the crack initiation. From the observed results, the microstructure with densely populated fine precipitates does not 
accelerate the crack propagation due probably to the high coherency between lattice parameters of the precipitate and austenite phases [30], which leads to low stress fields developed at the interface of small, nanometer range precipitates. On the other hand, for the samples with large precipitates, any externally applied stress on this type of microstructure leads to an increase in the local strain and stress, mainly at the tip of the large precipitates, which should enhance the crack propagation. Eventually, the latter samples become more brittle and fail at lower stress levels than the samples with fine precipitates. Similar observations were also reported in furnace cooled Ni-rich $\mathrm{Ni}_{50.3} \mathrm{Ti}_{29.7} \mathrm{Zr}_{20}$ samples consisting of large precipitates [8,9].

The recovered transformation strains and unrecovered strain levels (which is a measure of dimensional stability) of the aged $\mathrm{Ni}_{50.3} \mathrm{Ti}_{34.7} Z \mathrm{r}_{15}$ specimens are summarized as a function of applied bias stress in Fig. 8. The recovered transformation strain showed a continuous increase with increasing applied stress reaching approximately $2.5 \%$ for the NTZ500/200h, NTZ550/24h and NTZ550/100h samples under $300 \mathrm{MPa}$ applied stress. However, the NTZ600/100h sample failed while loading to 300 $\mathrm{MPa}$ and reached a maximum recovered transformation strain of only $1.2 \%$ under $250 \mathrm{MPa}$. The unrecovered strain levels were determined at temperatures $30^{\circ} \mathrm{C}$ above the $A_{f}$ temperature for each applied stress level, calculated as the difference in strain between the heating and cooling curves. Except the NTZ600/100h sample, all the aged samples show perfect dimensional stability up to $300 \mathrm{MPa}$ stress levels as a consequence of the increased resistance to plastic deformation due to precipitation hardening. These results suggest that no training is necessary for achieving dimensional stability in the present alloy since no bulk plastic deformation was evident during the first few cycles. However, because the precipitates are much larger after aging for $100 \mathrm{~h}$ at $600^{\circ} \mathrm{C}$, precipitation hardening is less prominent as compared to other aged samples with relatively smaller precipitates. Therefore, the NTZ600/100h sample exhibited unrecovered strain starting at $200 \mathrm{MPa}$ applied stress (0.05\%), which increased to $0.15 \%$ at $250 \mathrm{MPa}$. The significant resistance to plastic deformation in the 500 and $550{ }^{\circ} \mathrm{C}$ aged samples originates from the existence of nanosize precipitates, which have coarsened beyond an optimal size for strengthening in the NTZ600/100h sample. The present Ni-rich $\mathrm{Ni}_{50.3} \mathrm{Ti}_{34.7} \mathrm{Zr}_{15}$ alloy shows much better shape recovery than $(\mathrm{Ti}+\mathrm{Hf} / \mathrm{Zr}$ )-rich NiTiZr/Hf alloys $[12,42,43]$, while demonstrating comparable stability to other precipitation hardened Ni-rich NiTiZr/Hf alloys [8, 9, 32].

The maximum recovered transformation strains observed for the $\mathrm{Ni}_{50.3} \mathrm{Ti}_{34.7} \mathrm{Zr}_{15}$ alloy are less than values previously reported for several ternary Ni-rich NiTiHf alloys and binary NiTi. However, as seen in Fig. 8, the recovered transformation strain levels have not peaked or reached a plateau region with 
stress, indicating that the martensite reorientation/detwinning were not complete under the current applied stress levels. Therefore, the aged samples would be expected to generate higher recovered transformation strains at higher stresses. However, along with the increase in matrix hardness with precipitation, the samples were relatively brittle and failed at stress levels above $300 \mathrm{MPa}$. Therefore, the true extent of the recovered transformation strains for the alloy was not achieved for any of the aged conditions.

The effect of precipitation strengthening is also evident in the transformation thermal hysteresis values of the aged samples summarized in Fig. 9. As mentioned above, precipitation hardening was less prominent in the NTZ600/100h condition due to the larger precipitate sizes. This is consistent with the larger thermal hysteresis that was obtained in this sample, both under stress and zero stress conditions $\left(\Delta \mathrm{T}>50{ }^{\circ} \mathrm{C}\right)$ as compared to the samples with smaller precipitates $\left(\Delta \mathrm{T}<50{ }^{\circ} \mathrm{C}\right)$. It can also be argued that the increased number of precipitate-martensite variant interfaces, small martensite variants, and fine internal twins, due to the large precipitates, which acted as obstacles to martensite propagation in the NTZ600/100h samples, can result in increased energy dissipation and thus contribute to a larger thermal hysteresis as compared to the samples with small precipitates and large martensite variants.

The thermal hysteresis decreased in all the aged samples up to $150 \mathrm{MPa}$ and changed only slightly thereafter with further loading for the NTZ500/200h, NTZ550/24h and NTZ550/100h samples. However, in the case of NTZ600/100h sample, the initial decrease in the hysteresis up to $150 \mathrm{MPa}$ was followed by an increase above $150 \mathrm{MPa}$ that is consistent with the increase in unrecovered strain levels observed in Fig. 8. Thus, the generation of defects such as dislocations under applied stress levels of $200 \mathrm{MPa}$ and above, are responsible for this increase in thermal hysteresis. Finally, the overall range of thermal hysteresis values obtained in the aged $\mathrm{Ni}_{50.3} \mathrm{Ti}_{34.7} \mathrm{Zr}_{15}$ samples shown in Fig. 9 is comparable to that observed in a Ni-rich $\mathrm{Ni}_{50.3} \mathrm{Ti}_{34.7} \mathrm{Hf}_{15}$ alloy [32].

It should be noted that the thermal hysteresis values obtained from the stress free DSC experiments (calculated as $A_{f}-M_{s}$ and shown in Fig. 5b) are $10{ }^{\circ} \mathrm{C}$ larger than the zero stress thermal hysteresis levels measured from load-biased thermal cycling experiments (shown in Fig. 9). Basically, the hysteresis is determined at the onset and completion of the transformation in DSC, while the hysteresis is computed at about 50\% transformation level (calculated as the width between the midpoints of the heating and cooling curves as demonstrated in Fig. 7e). Moreover, in DSC, the transformation indicator is the latent heat, whereas it is the shape change, i.e., tensile strain, in the load-biased thermal cycling 
experiments. In some cases, even though the transformation starts and the latent heat can be measured, shape change may still not occur due to the formation of self-accommodating martensite. Therefore, differences in zero stress thermal hysteresis levels measured from DSC and load-biased thermal cycling experiments can be expected.

The change in $M_{s}$ temperature as a function of applied stress, i.e., Clausius-Clapeyron (CC) relationship, with the best linear fit lines for the aged samples is given in Fig. 10. As seen in Fig. 10, $M_{s}$ actually follows a bilinear relationship with different fits at low and high stresses. At low stress levels, as a consequence of the relatively soft austenite phase and martensite variant-variant interactions, due to the co-existence of self-accommodated and oriented martensite variants, local defects may be generated leading to energy dissipation. Therefore, $M_{s}$ temperature shows a decrease in NTZ550/24h and NTZ600/100h cases with increasing stress for the stress levels less than $100 \mathrm{MPa}$. In the case of NTZ500/200h and NTZ550/24h samples, there is almost no change in $\mathrm{M}_{\mathrm{s}}$ with stress below $100 \mathrm{MPa}$. There seems to be a direct correlation between the precipitate size / austenite strength and the deviation from the critical stress for martensitic transformation vs. temperature slope in Fig. 10, i.e. the stronger the matrix is, the less deviation from the CC slope occurs at low stress levels. Similar observations were also reported for ternary NiTiHf [32] and binary NiTi [44] alloys, where the aforementioned deviation was reduced and eventually conventional linear CC relationship was obtained at all stress levels when the austenite strength was increased by either precipitation hardening (peak aging) or grain size refinement.

For stresses greater than $100 \mathrm{MPa}$, the $\mathrm{M}_{\mathrm{s}}$ of all four cases exhibit a linear stress dependence with $\mathrm{CC}$ slopes of $13.7 \mathrm{MPa} /{ }^{\circ} \mathrm{C}, 8.4 \mathrm{MPa} /{ }^{\circ} \mathrm{C}, 14.8 \mathrm{MPa} /{ }^{\circ} \mathrm{C}$ and $23.7 \mathrm{MPa} /{ }^{\circ} \mathrm{C}$, respectively. Furthermore, as seen in Fig. 10, higher stresses are needed to increase $M_{s}$ in the sample with large precipitates (NTZ600/100h with the $\mathrm{CC}$ slope of $23.7 \mathrm{MPa} /{ }^{\circ} \mathrm{C}$ ) as compared to the samples with smaller precipitates. The exact reason for such high CC slope in the sample with large precipitates and different martensite morphology is not completely known. However, three factors should play a role: (1) changes in martensitic transformation - precipitate interactions as a result of the coherency loss with increasing precipitate size and associated changes in strain energy around the precipitates; (2) the change in the matrix strength and composition with the increase in precipitate size and volume fraction; and (3) the change in martensite morphology and variant / twin size with increasing precipitate size. Clearly, more systematic work is needed to understand the role of martensite morphology and precipitate size on the stress vs. temperature phase diagrams of these SMAs. 


\section{Summary and Conclusions}

The present work reports on the effect of precipitation on the microstructure and shape memory properties of the Ni-rich $\mathrm{Ni}_{50.3} \mathrm{Ti}_{34.7} Z \mathrm{Zr}_{15}$ alloy for the first time. Based on the reported experimental results, the following conclusions can be made:

1. Spindle-shaped precipitates form after aging at $500{ }^{\circ} \mathrm{C}, 550{ }^{\circ} \mathrm{C}$ and $600{ }^{\circ} \mathrm{C}$. Martensite variants may easily grow and absorb the relatively smaller precipitates $(<160 \mathrm{~nm})$ during transformation while several hundred nanometer long precipitates, which form after aging at $600{ }^{\circ} \mathrm{C}$, strongly interfere with martensite variant growth and results in a refined twin structure. The precipitate crystal structure was found to be the same as the $\mathrm{H}$-type precipitates previously identified in $\mathrm{Ni}$ rich NiTiHf and NiTiZr alloys.

2. The transformation temperatures of the $\mathrm{Ni}_{50.3} \mathrm{Ti}_{34.7} \mathrm{Zr}_{15}$ alloy can be modified over a wide range as a consequence of the change in matrix composition due to the precipitation. The stress free thermal hysteresis of the aged samples varies between $53-66{ }^{\circ} \mathrm{C}$ and is comparable to Ni-rich $\mathrm{NiTiHf}$ alloys with similar compositions and stoichiometry.

3. Aged $\mathrm{Ni}_{50.3} \mathrm{Ti}_{34.7} \mathrm{Zr}_{15}$ samples with relatively smaller precipitates $(<160 \mathrm{~nm})$ show excellent dimensional stability and a maximum of $2.5 \%$ transformation strain under applied stress levels as high as $300 \mathrm{MPa}$. The precipitation hardening was less prominent in aged samples with precipitates several hundred nanometers in size, resulting in unrecovered strain during thermomechanical cycling at stresses equal to or greater than $200 \mathrm{MPa}$. Samples with large precipitates also exhibit higher thermal hysteresis due to the increased number of precipitatemartensite interfaces and finer variants and internal twins with a contribution at higher stresses due to the onset of plasticity during thermomechanical cycling. Finally, the CC slope for the sample with the largest precipitates (NTZ600/100h with a CC slope of $23.7 \mathrm{MPa} /{ }^{\circ} \mathrm{C}$ ) was 2-3 times larger than that for samples with relatively finer precipitates, which ranged from 8.4 to 14.8 MPa/ ${ }^{\circ} \mathrm{C}$ for all other aged samples.

4. Although the DSC results indicated that the thermal stability of the present $\mathrm{Ni}_{50.3} \mathrm{Ti}_{34.7} \mathrm{Zr}_{15} \mathrm{SMA}$ is inferior to the comparable Ni-rich $\mathrm{Ni}_{50.3} \mathrm{Ti}_{34.7} \mathrm{Hf}_{15}$ alloy [32], overall the microstructure and the shape memory response of the aged $\mathrm{Ni}_{50.3} \mathrm{Ti}_{34.7} \mathrm{Zr}_{15}$ alloy was similar to its NiTiHf counterpart. Considering the fact that $\mathrm{Zr}$ also provides weight and cost savings compared to Hf, NiTiZr alloys 
could be viable alternatives to NiTiHf alloys for high temperature shape memory alloy applications and warrant further study.

\section{Acknowledgements}

The present study was supported by the US Air Force Office of Scientific Research, under Grant No. FA9550-15-1-0287. Additional support was received from the National Science Foundation under Grant No. CMMI 1534534, and under Grant No. DMR 08-44082, which supports the International Materials Institute for Multifunctional Materials for Energy Conversion (IIMEC) at Texas A\&M University. Partial financial support from the Spanish MINECO and FEDER under Project Number MAT2011-28217-C02-01 are also acknowledged. RDN gratefully acknowledges support from the NASA Transformative Aeronautics Concepts Program, Transformational Tools \& Technologies Project (Dale Hopkins, Technical Lead for Structures \& Materials Discipline).

\section{References}

[1] K. Otsuka, X. Ren, Physical metallurgy of Ti-Ni-based shape memory alloys, Prog. Mater. Sci. 50 (2005) 511-678.

[2] K. Otsuka, X. Ren, Recent developments in the research of shape memory alloys, Intermetallics 7 (1999) 511-528.

[3] K. Otsuka, C.M. Wayman, Shape Memory Materials, Cambridge University Press, Cambridge, U.K., 1999.

[4] L.G. Machado, M.A. Savi, Medical applications of shape memory alloys, Braz. J. Med. Biol. Res. 36 (2003) 683-691.

[5] S.I. Padula, S. Qiu, D. Gaydosh, R. Noebe, G. Bigelow, A. Garg, R. Vaidyanathan, Effect of upper-cycle temperature on the load-biased, strain-temperature response of NiTi, Metall. Mater. Trans. A 43 (2012) 4610-4621.

[6] J. Ma, I. Karaman, R.D. Noebe, High temperature shape memory alloys, International Materials Reviews 55 (2010) 257-315.

[7] B. Kockar, I. Karaman, J.I. Kim, Y.I. Chumlyakov, A method to enhance cyclic reversibility of NiTiHf high temperature shape memory alloys, Scripta Mater. 54 (2006) 2203-2208. 
[8] A. Evirgen, I. Karaman, R.D. Noebe, R. Santamarta, J. Pons, effect of precipitation on the microstructure and the shape memory response of the $\mathrm{Ni}_{50.3} \mathrm{Ti}_{29.7} \mathrm{Zr}_{20}$ high temperature shape memory alloy, Scripta Mater. 69 (2013) 354-357.

[9] A. Evirgen, I. Karaman, R. Santamarta, J. Pons, R.D. Noebe, Microstructural characterization and superelastic response of a $\mathrm{Ni}_{50.3} \mathrm{Ti}_{29.7} Z \mathrm{Zr}_{20}$ high-temperature shape memory alloy, Scripta Mater. 81 (2014) $12-15$.

[10] K.H. Eckelmeyer, The effect of alloying on the shape memory phenomenon in Nitinol, Scripta Metall. 10 (1976) 667-672.

[11] J. Mulder, PhD Thesis, University of Twente, Enschede, The Netherlands; 1994.

[12] S.F. Hsieh, S.K. Wu, A study on ternary Ti-rich TiNiZr shape memory alloys, Mater. Charact. 41 (1998) 151-162.

[13] S.F. Hsieh, S.K. Wu, A study on lattice parameters of martensite in $\mathrm{Ti}_{50.5-\mathrm{x}} \mathrm{Ni}_{49.5} \mathrm{Zr}_{\mathrm{x}}$ shape memory alloys, J. Alloys Compd. 270 (1998) 237-241.

[14] S.F. Hsieh, S.K. Wu, Room-temperature phases observed in $\mathrm{Ti}_{53-\mathrm{x}} \mathrm{Ni}_{47} \mathrm{Zr}_{\mathrm{x}}$ high temperature shape memory alloys, J. Alloys Compd. 266 (1998) 276-282.

[15] G.S. Firstov, J.V. Humbeeck, Comparison of high temperature shape memory behavior for ZrCubased, Ti-Ni-Zr and Ti-Ni-Hf alloys, Y.N. Koval, Scripta Mater. 50 (2004) 243-248.

[16] S.F. Hsieh, S.K. Wu, Martensitic transformation of quaternary $\mathrm{Ti}_{50.5-\mathrm{x}} \mathrm{Ni}_{49.5} \mathrm{Zr}_{\mathrm{x} / 2} \mathrm{Hf}_{\mathrm{x} / 2}(\mathrm{x}=0-20$ at.\%) shape memory alloys, Mater. Charac. 45 (2000) 143-152.

[17] Z. Pu, H. Tseng, K. Wu, Martensite transformation and shape memory effect of NiTi-Zr high temperature shape memory alloys, SPIE Proc., 2441 (1995) 171-178.

[18] S.K. Wu, S.F. Hsieh, Martensitic transformation of a Ti-rich $\mathrm{Ti}_{40.5} \mathrm{Ni}_{49.5} \mathrm{Zr}_{10}$ shape memory alloy, J. Alloys Compd., 297 (2000) 294-302.

[19] J. Khalil-Allafi, A. Dlouhy, G. Eggeler, $\mathrm{Ni}_{4} \mathrm{Ti}_{3}$-precipitation during aging of NiTi shape memory alloys and its influence on martensitic phase transformations, Acta Mater. 50 (2002) 4255-4274.

[20] K. Gall, H. Sehitoglu, Y.I. Chumlyakov, Y.L. Zuev, I. Karaman, The role of coherent precipitates in martensitic transformations in single crystal and polycrystalline Ti-50.8at\%Ni, Scripta Mater. 39 (1998) 699-705.

[21] E.Y Panchenko, Y.I. Chumlyakov, I.V. Kireeva, A.V. Ovsyannikov, H. Sehitoglu, I. Karaman, Y.H.J. Maier, effect of disperse $\mathrm{Ti}_{3} \mathrm{Ni}_{4}$ particles on the martensitic transformations in Titanium Nickelide single crystals, Phys. Metall. Metallogr. 106 (2008) 577-589.

[22] J.I. Kim, S. Miyazaki, Effect of nano-scaled precipitates on shape memory behavior of Ti-50.9at.\%Ni 
alloy, Acta Mater. 53 (2005) 4545-4554.

[23] M. Nishida, C.M. Wayman, T. Honma, Precipitation processes in near-equatomic TiNi shape memory alloys, Metall Trans 17A (1986) 1505-1515.

[24] H. Sehitoglu, I. Karaman, R. Anderson, X.Y. Zhang, Y.I. Chumlyakov, Compressive response of NiTi single crystals, Acta Mater. 48 (2000) 3311-3326.

[25] H. Sehitoglu, J. Jun, X.Y. Zhang, I. Karaman, Y.I. Chumlyakov, H.J. Maier, K. Gall, Shape memory and pseudoelastic behavior of 51.5\% Ni-Ti single crystals in solutionized and overaged state, Acta Mater. 49 (2001) 3609-3620.

[26] K. Gall, H. Sehitoglu, R. Anderson, I. Karaman, Y.I. Chumlyakov, I.V. Kireeva, On the mechanical behavior of single crystal NiTi shape memory alloys and related polycrystalline phenomenon, Mater. Sci. Eng. A 317 (2001) 85-92.

[27] H. Sehitoglu, R. Anderson, I. Karaman, K. Gall, Y.I. Chumlyakov, Cyclic deformation behavior of single crystal NiTi, Mater. Sci. Eng. A 314 (2001) 67-74.

[28] A.M. Sandu, K. Tsuchiya, S. Yamamoto, Y. Todaka, M. Umemoto, Influence of isothermal ageing on mechanical behaviour in Ni-rich Ti-Zr-Ni shape memory alloy, Scr. Mater. 55 (2006) 1079-1082.

[29] A.M. Sandu, K. Tsuchiya, M. Tabuchi, S. Yamamoto, Y. Todaka, M. Umemoto, Microstructural evolution during isothermal aging in Ni-rich Ti-Zr-Ni shape memory alloys, Mater. Trans. 48 (2007) 432-438.

[30] R. Santamarta, R. Arroyave, J. Pons, A. Evirgen, I. Karaman, H.E. Karaca, R.D. Noebe, TEM study of structural and microstructural characteristics of a precipitate phase in $\mathrm{Ni}-\mathrm{rich} \mathrm{Ni}-\mathrm{Ti}-\mathrm{Hf}$ and $\mathrm{Ni}-\mathrm{Ti}-\mathrm{Zr}$ shape memory alloys, Acta Mater. 61 (2013) 6191-6206.

[31] M. Nishida, C.M. Wayman, A. Chiba, Electron microscopy studies of the martensitic transformation in an aged ti-51at\%Ni shape memory alloy, Metallogr. 21 (1988) 275-291.

[32] A. Evirgen, I. Karaman, R. Santamarta, J. Pons, R.D. Noebe, Microstructural characterization and shape memory characteristics of the $\mathrm{Ni}_{50.3} \mathrm{Ti}_{34.7} \mathrm{Hf}_{15}$ shape memory alloy, Acta Mater. 83 (2015) 48-60.

[33] J. Pons, E. Cesari, Martensitic transformation cycling in a $\beta \mathrm{Cu}-\mathrm{Zn}$-Al alloy containing $\gamma$-precipitates, Acta Met. Mater. 41 (1993) 2547-2555.

[34] E. Cesari, J. Pons, M. Chandrasekaran, The influence of $\gamma$ precipitates on the martensitic transformation and related effects in Cu-based shape memory alloys, Trans. Mat. Res. Soc Jpn. 18B (1994) 903-909.

[35] I.V. Kireeva, J. Pons, C. Picornell, Y.I. Chumlyakov, E. Cesari, I.V. Kretinina, Influence of $\gamma^{\prime}$ nanometric particles on martensitic transformation and twinning structure of $\mathrm{L}_{0}$ martensite in Co-Ni-Ga 
ferromagnetic shape memory single crystals, (2013) 60-66.

[36] F. Yang, D.R. Coughlin, P.J. Phillips, L. Yang, A. Devaraj, L. Kovarik, R.D. Noebe, M.J. Mills, Structure analysis of a precipitate phase in an Ni-rich high-temperature NiTiHf shape memory alloy, Acta Mater. 61 (2013) 3335-3346.

[37] M. Moshref-Javadi, S.H. Seyedein, T. Salehi, M.R. Aboutalebi, Age-induced multi-stage transformation in a Ni-rich NiTiHf alloy, Acta Mater. 61 (2013) 2583-2594.

[38] X. Meng, W. Cai, Y. Zheng, L. Zhao, Phase transformation and precipitation in aged Ti-Ni-Hf hightemperature shape memory alloys, Mater. Sci. Eng. A 438 (2006) 666-670.

[39] X. Meng, W. Cai, F. Chen, L.C. Zhao, Effect of aging on martensitic transformation and microstructure in Ni-rich TiNiHf shape memory alloy, Scr. Mater. 54 (2006) 1599-1604.

[40] X.L. Meng, W. Cai, Y.D. Fu, Q.F. Li, J.X. Zhang, L.C. Zhao, Shape-memory behaviors in an aged Ni-rich TiNiHf high temperature shape-memory alloy, Intermetall. 16 (2008) 698-705.

[41] A. Evirgen, F. Basner, I. Karaman, R.D. Noebe, J. Pons, R. Santamarta, Effect of aging on the martensitic transformation characteristics of a Ni-rich NiTiHf high temperature shape memory alloy, Funct. Mater. Lett. 5 (2012) 1250038 pp 1-5.

[42] X.L. Meng, Y.F. Zheng, Z. Wang, L.C. Zhao, Shape memory properties of the $\mathrm{Ti}_{36} \mathrm{Ni}_{49} \mathrm{Hf}_{15}$ high temperature shape memory alloy, Mater. Lett. 45 (2000) 128-132.

[43] X.L. Meng, Y.F. Zheng, Z. Wang, L.C. Zhao, effect of aging on the phase transformation and mechanical behavior of $\mathrm{Ti}_{36} \mathrm{Ni}_{49} \mathrm{Hf}_{15}$ high temperature shape memory alloy, Scr. Mater. 42 (2000) 341348.

[44] B. Kockar, I. Karaman, J.I. Kim, Y.I. Chumlyakov, J. Sharp, C.J. Yu, Thermomechanical cyclic response of an ultrafine-grained NiTi shape memory alloy, Acta Mater. 56 (2008) 3630-3646. 


\section{FIGURES}

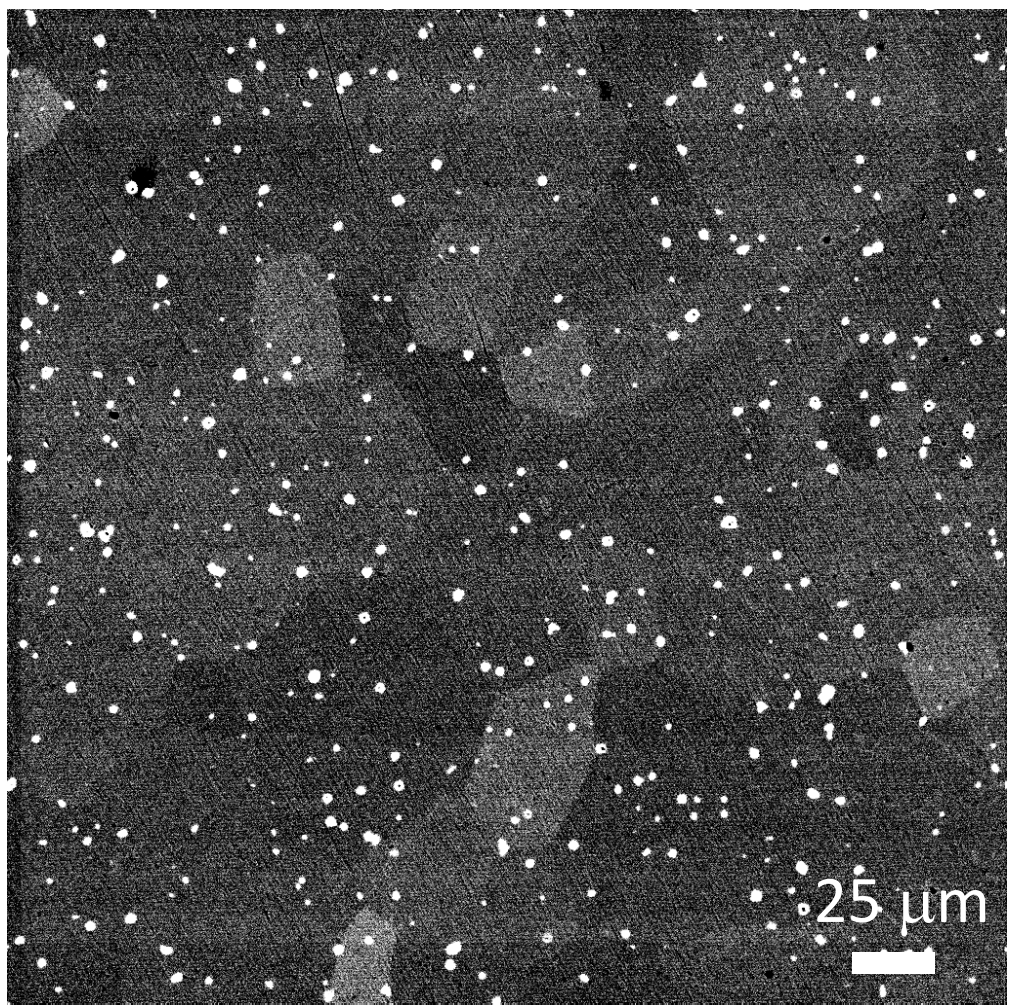

Figure 1: Back-scattered electron micrograph of the solution heat treated (SHT) $\mathrm{Ni}_{50.3} \mathrm{Ti}_{34.7} \mathrm{Zr}_{15} \mathrm{SMA}$. White particles are carbide inclusions (mainly $\mathrm{ZrC}$ ). No other second phases were observed in the microstructure at this scale. The austenite grain size ranges from $25 \mu \mathrm{m}$ to $100 \mu \mathrm{m}$. 

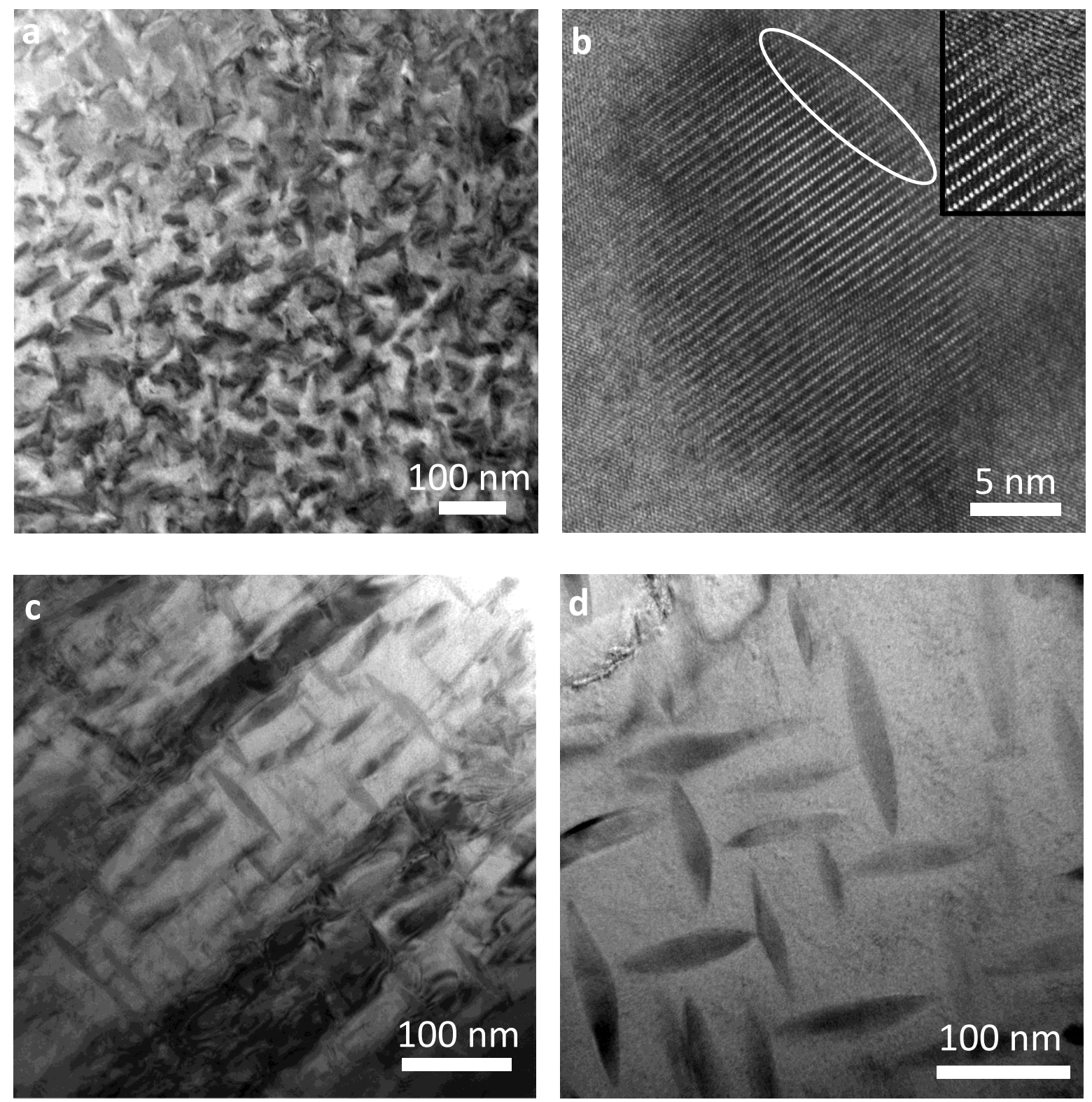

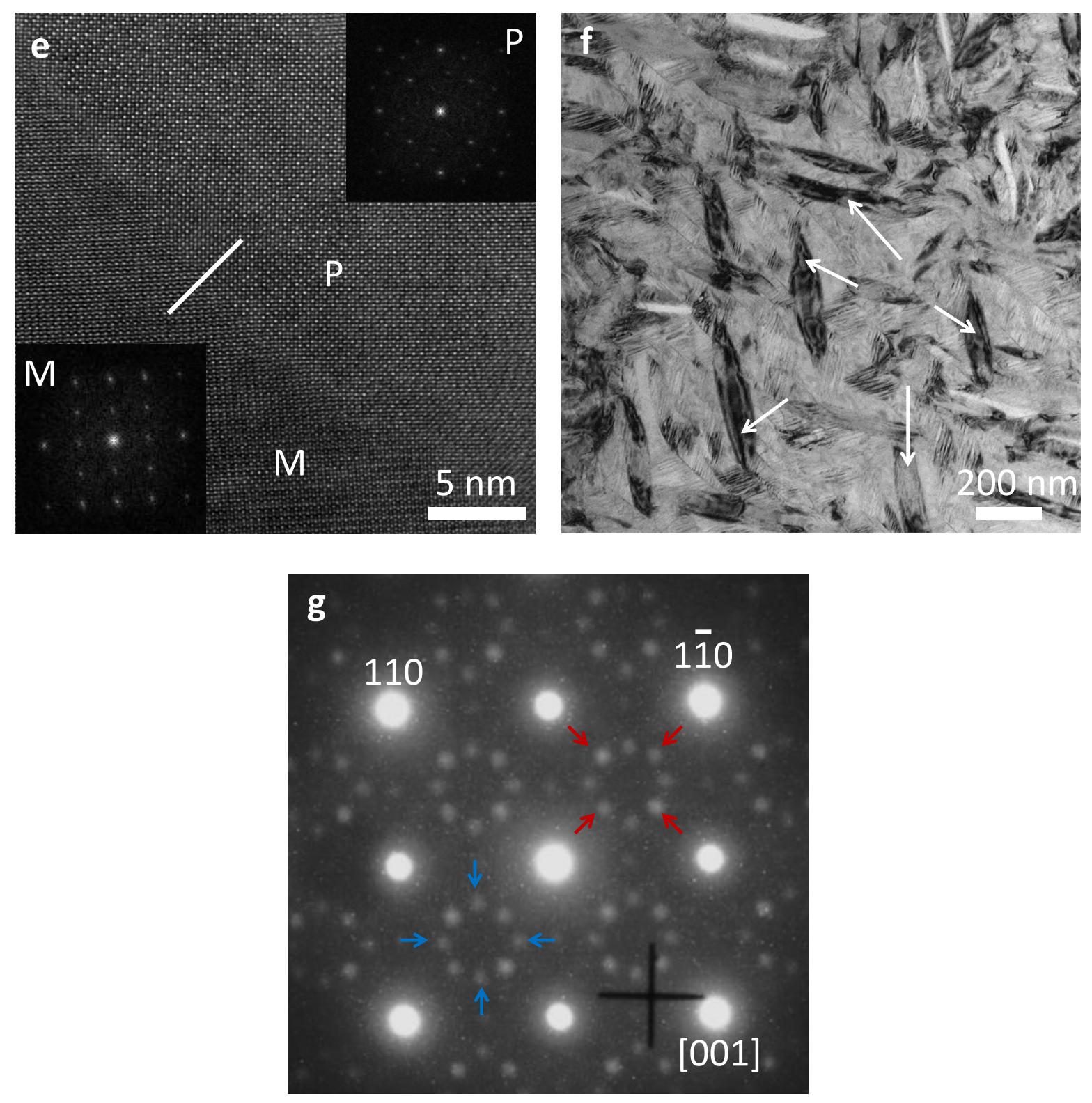

Figure 2: Bright field transmission electron microscopy images of $\mathrm{Ni}_{50.3} \mathrm{Ti}_{34.7} \mathrm{Zr}_{15}$ (at.\%): (a) sample aged at $500^{\circ} \mathrm{C}$ for $200 \mathrm{~h}$, (b) HRTEM image of the precipitate - B2 interface in the sample aged at $500^{\circ} \mathrm{C}$ for 200 h, (c) sample aged at $550^{\circ} \mathrm{C}$ for $24 \mathrm{~h}$, (d) sample aged at $550^{\circ} \mathrm{C}$ for $100 \mathrm{~h}$, (e) HRTEM image of the precipitate - B19' interface and the corresponding FFT images of the sample aged at $550^{\circ} \mathrm{C}$ for $100 \mathrm{~h}$ and (f) sample aged at $600^{\circ} \mathrm{C}$ for $100 \mathrm{~h}$. A white line is drawn to show continuity of atomic planes at the interface in image (e) and the precipitates are marked with arrows in image (f). (g) The SADP image taken from the sample aged at $550^{\circ} \mathrm{C}$ for $100 \mathrm{~h}$, consisting of two variants of $\mathrm{H}$-phase precipitates with $1 / 3<110>$ satellites (red arrows) and another two variants with $1 / 4<210>$ satellites (blue arrows). 


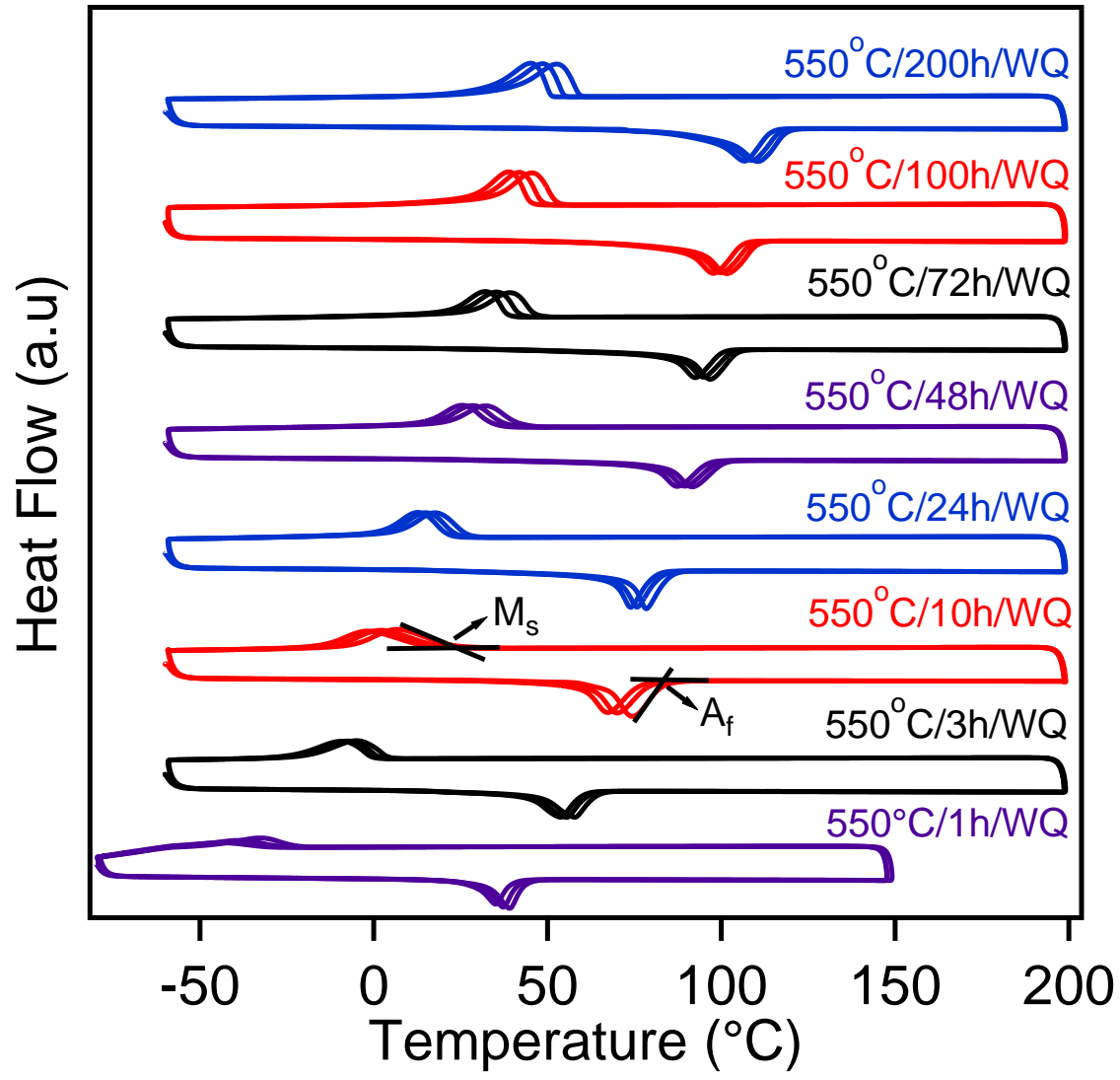

Figure 3: Representative DSC curves for $\mathrm{Ni}_{50.3} \mathrm{Ti}_{34.7} \mathrm{Zr}_{15}$ samples aged at $550^{\circ} \mathrm{C}$ for various times. Each case consists of three heating-cooling cycles. The $A_{f}$ and $M_{s}$ temperatures were measured using the intercept method as demonstrated on the DSC curve of the sample aged at $550^{\circ} \mathrm{C}$ for $10 \mathrm{~h}$. 


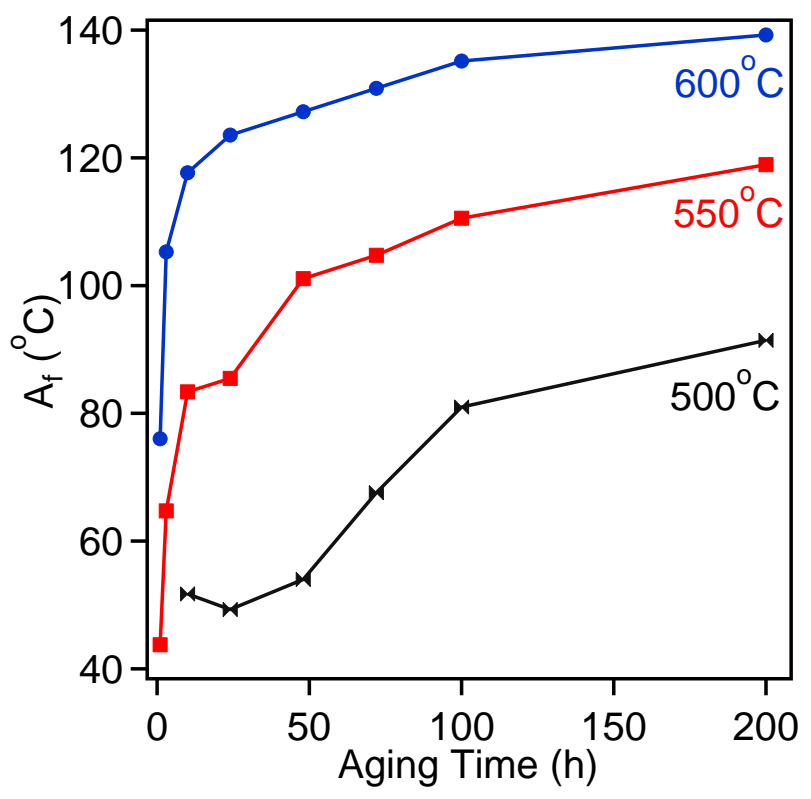

(a)

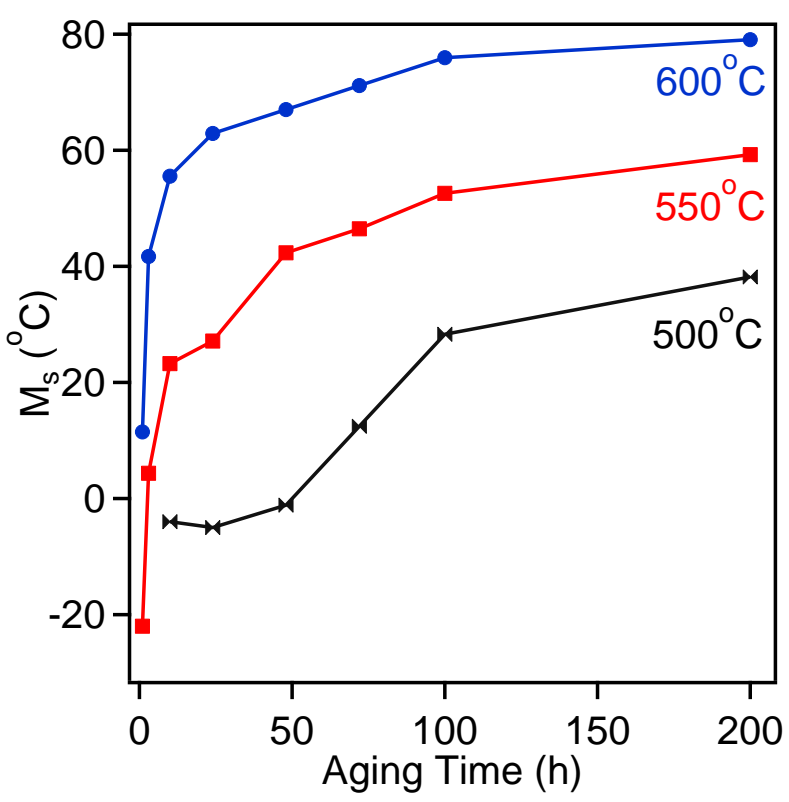

(b)

Figure 4: Summary of the transformation temperatures for $\mathrm{Ni}_{50.3} \mathrm{Ti}_{34.7} \mathrm{Zr}_{15}$ samples aged at $500^{\circ} \mathrm{C}, 550^{\circ} \mathrm{C}$ and $600^{\circ} \mathrm{C}$ for different times: (a) Austenite finish $\left(A_{f}\right)$ temperatures and (b) Martensite start $\left(M_{s}\right)$ temperatures. 


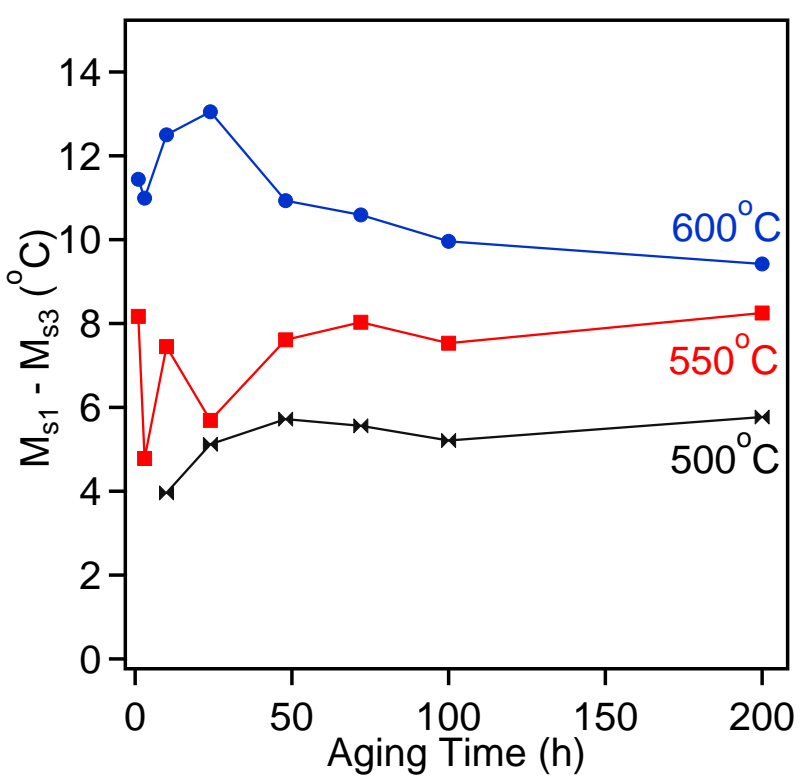

(a)

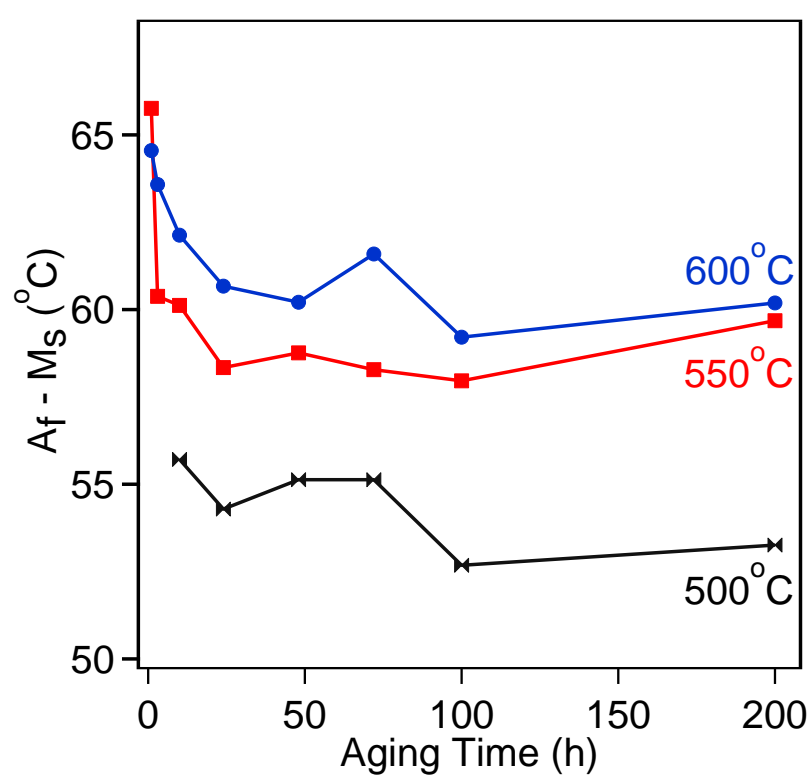

(b)

Figure 5: Summary of $(a)$ the shift in $M_{s}\left(M_{s 1}-M_{s 3}\right)$ temperatures during stress free DSC cycling, and (b) the thermal hysteresis $\left(A_{f}-M_{s}\right)$ of the $\mathrm{Ni}_{50.3} \mathrm{Ti}_{34.7} \mathrm{Zr}_{15}$ alloy aged at $500^{\circ} \mathrm{C}, 550^{\circ} \mathrm{C}$ and $600^{\circ} \mathrm{C}$ for various durations. 


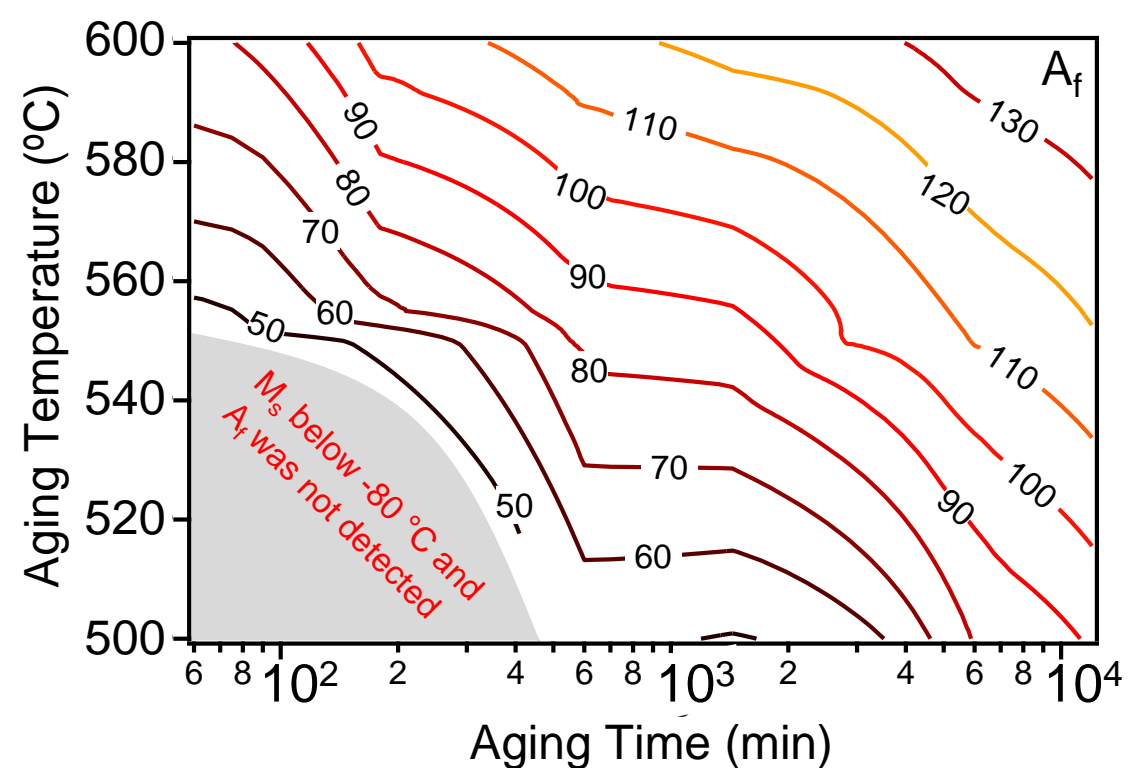

(a)

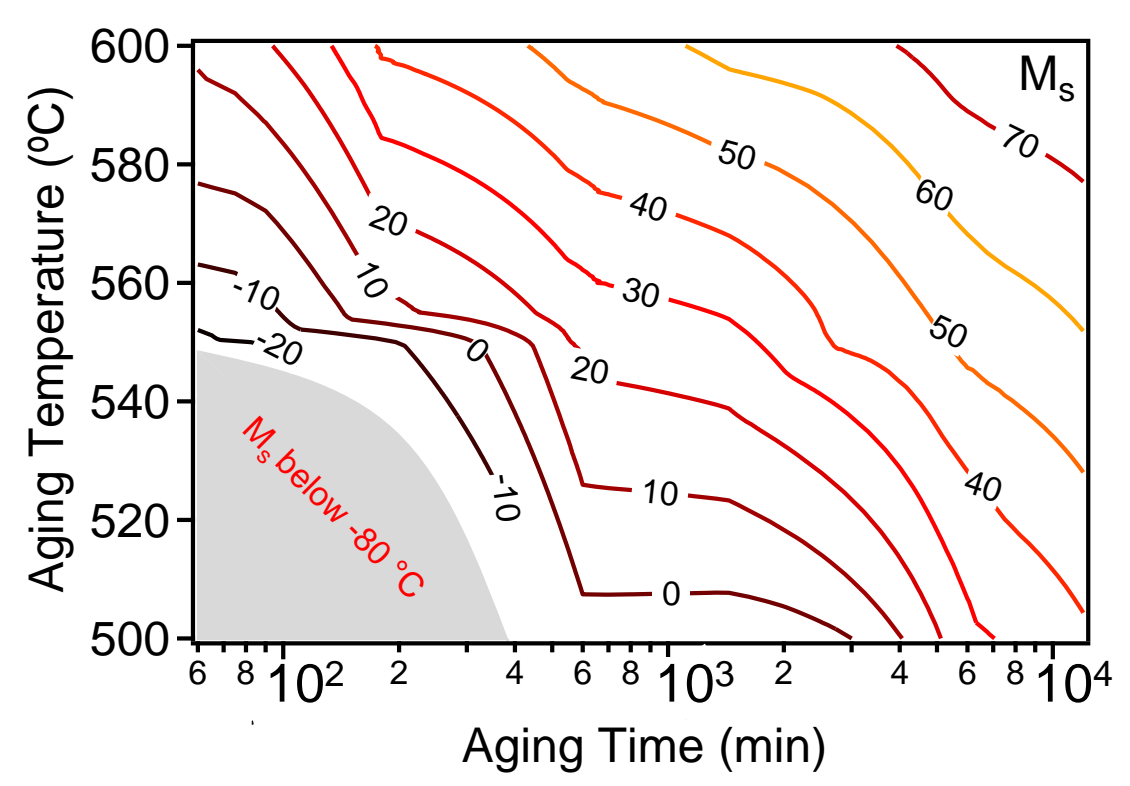

(b)

Figure 6: Aging time-temperature-martensitic transformation temperature diagrams revealing the effect of aging temperature and time on the $A_{f}(a)$ and $M_{s}(b)$ temperatures of the $\mathrm{Ni}_{50.3} \mathrm{Ti}_{34.7} \mathrm{Zr}_{15} \mathrm{SMA}$. The data is derived from the DSC measurements and plotted as lines of constant transformation temperatures. 


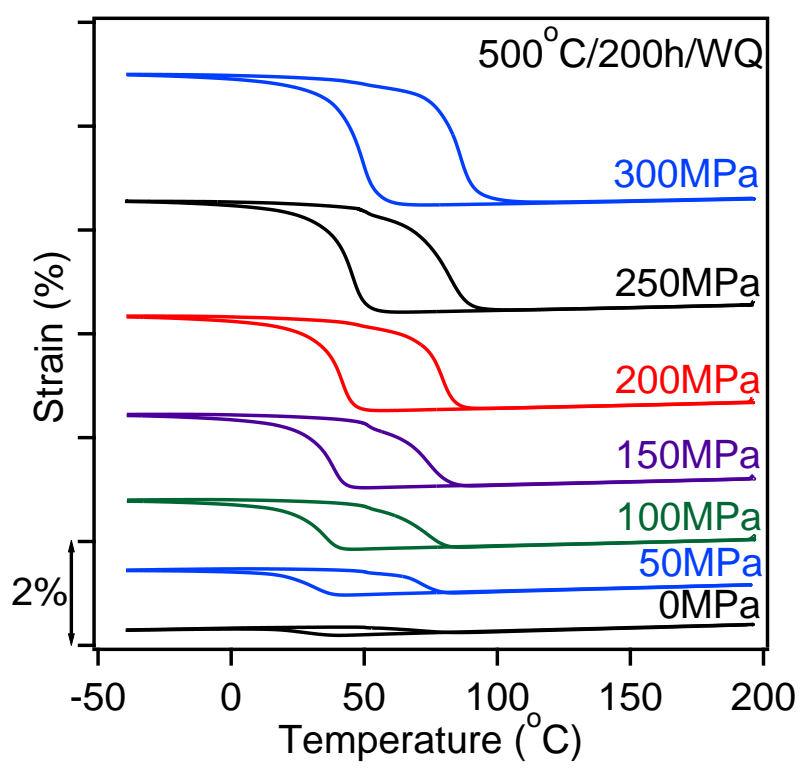

(a)

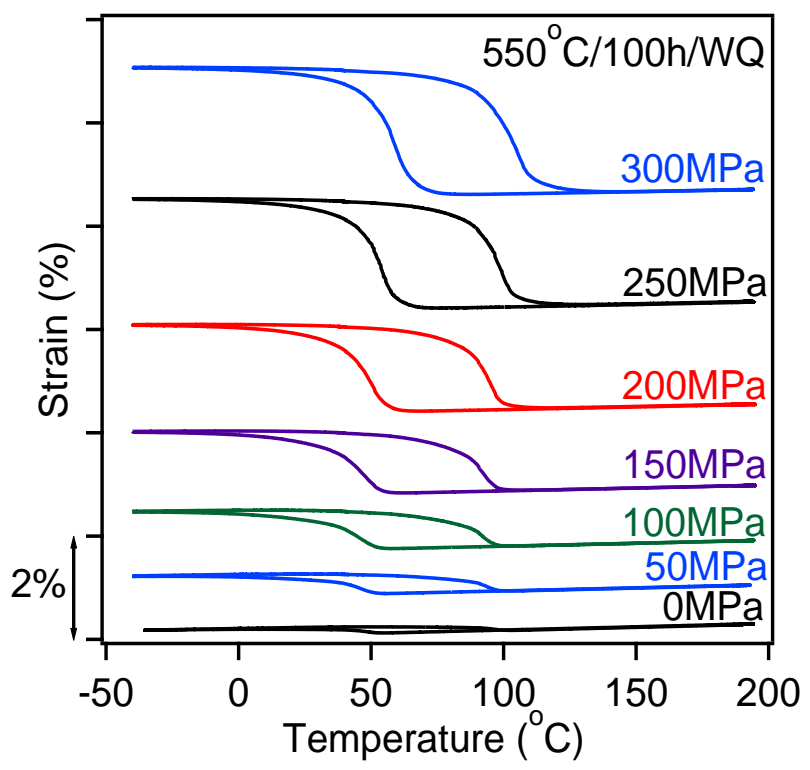

(c)

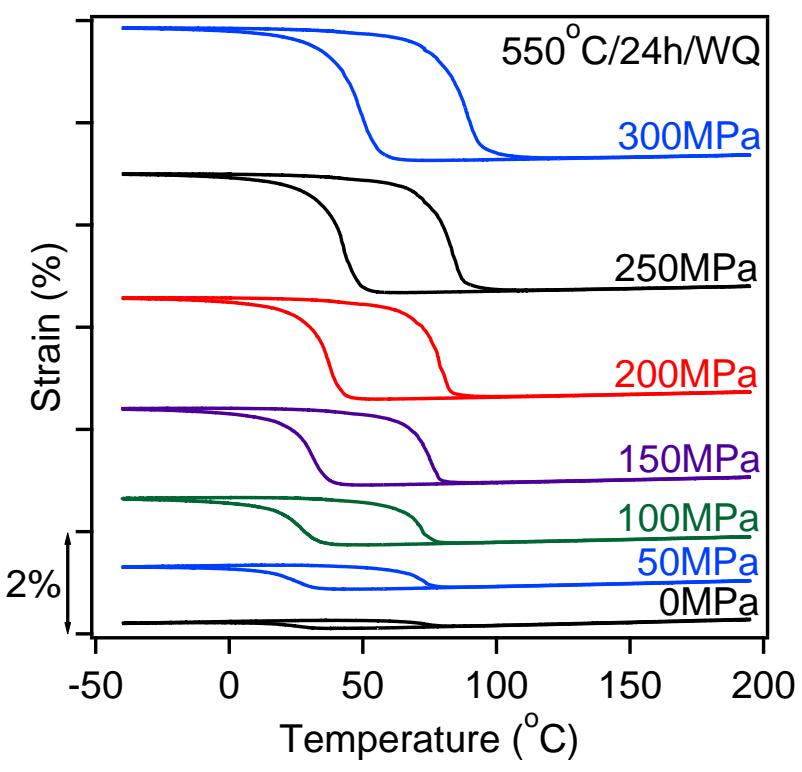

(b)

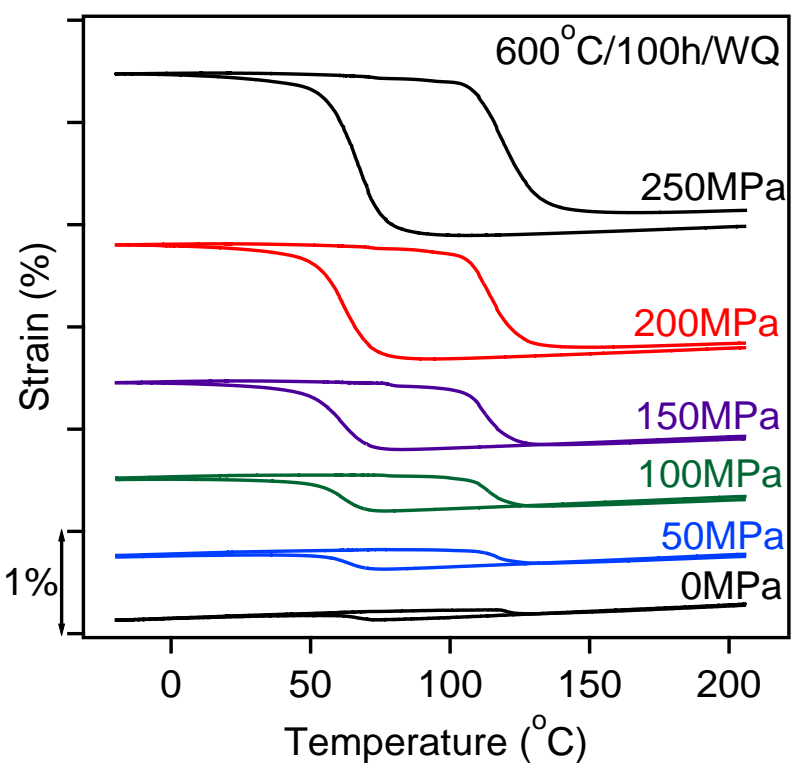

(d) 


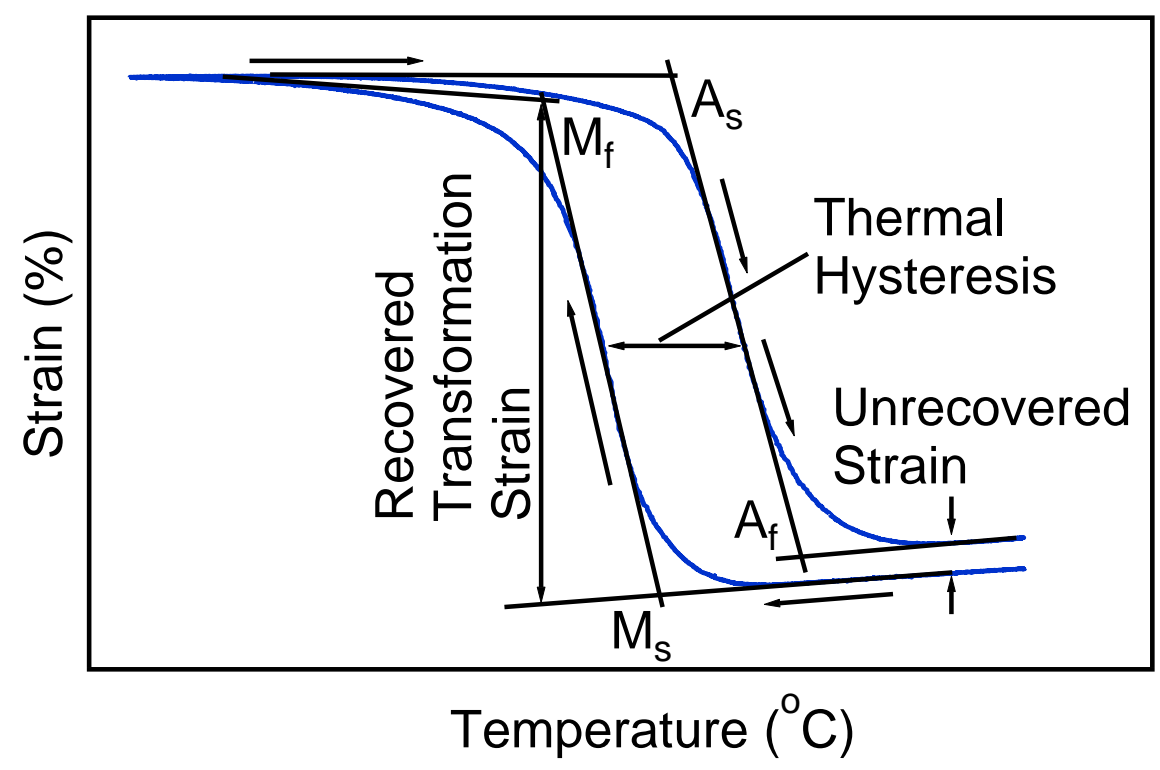

(e)

Figure 7: The strain vs. temperature responses of aged $\mathrm{Ni}_{50.3} \mathrm{Ti}_{34.7} \mathrm{Zr}_{15}$ samples under various tensile stress levels: a) aged at $500^{\circ} \mathrm{C}$ for $200 \mathrm{~h}, \mathrm{~b}$ ) aged at $550^{\circ} \mathrm{C}$ for $24 \mathrm{~h}, \mathrm{c}$ ) aged at $550^{\circ} \mathrm{C}$ for $100 \mathrm{~h}$ and d) aged at $600^{\circ} \mathrm{C}$ for $100 \mathrm{~h}$. (e) Schematic representation of how the shape memory characteristics are determined from the load-biased thermo-mechanical cycling experiments in tension. The figure shows one thermal cycle at a constant stress level. $M_{s}$ and $M_{f}$ indicate the martensite start and martensite finish temperatures, respectively, and $A_{s}$ and $A_{f}$ refer to austenite start and austenite finish temperatures, respectively. The thermal hysteresis is calculated as the width between the midpoints of the heating and cooling curves. 


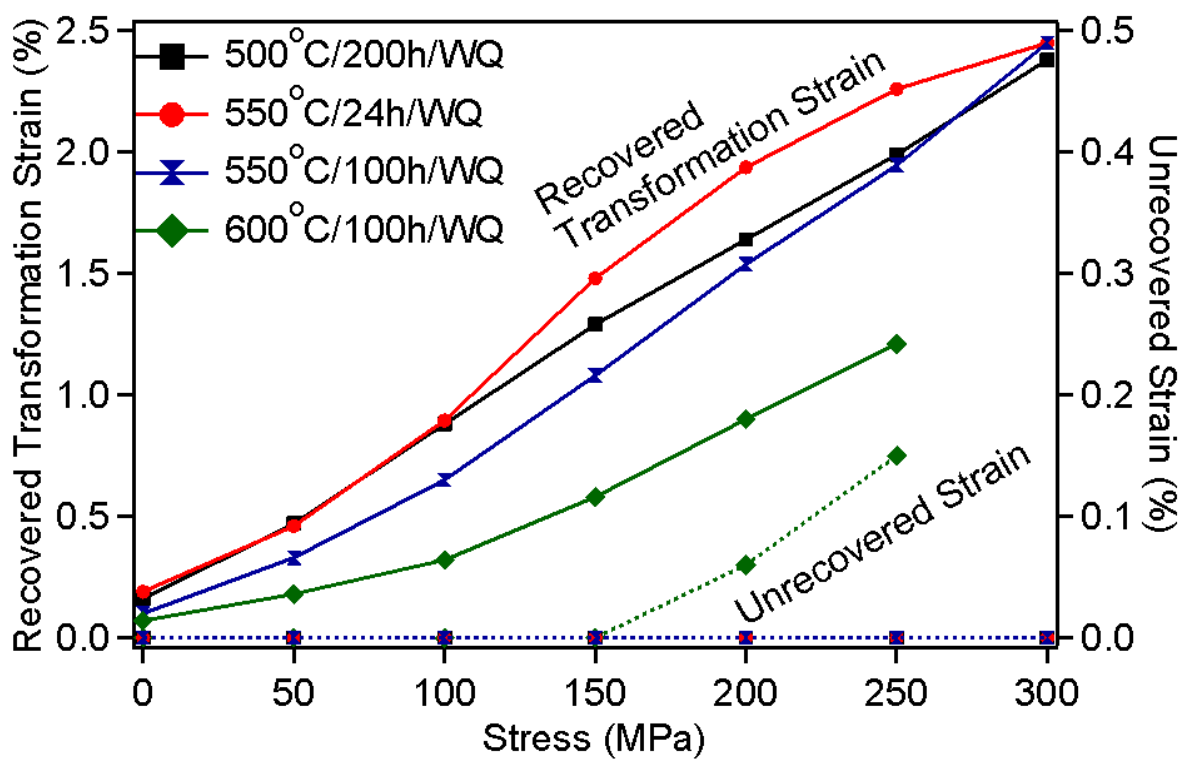

Figure 8: Summary of the recovered transformation strains and unrecovered strain levels for aged $\mathrm{Ni}_{50.3} \mathrm{Ti}_{34.7} \mathrm{Zr}_{15}$ samples as a function of applied tensile stress.

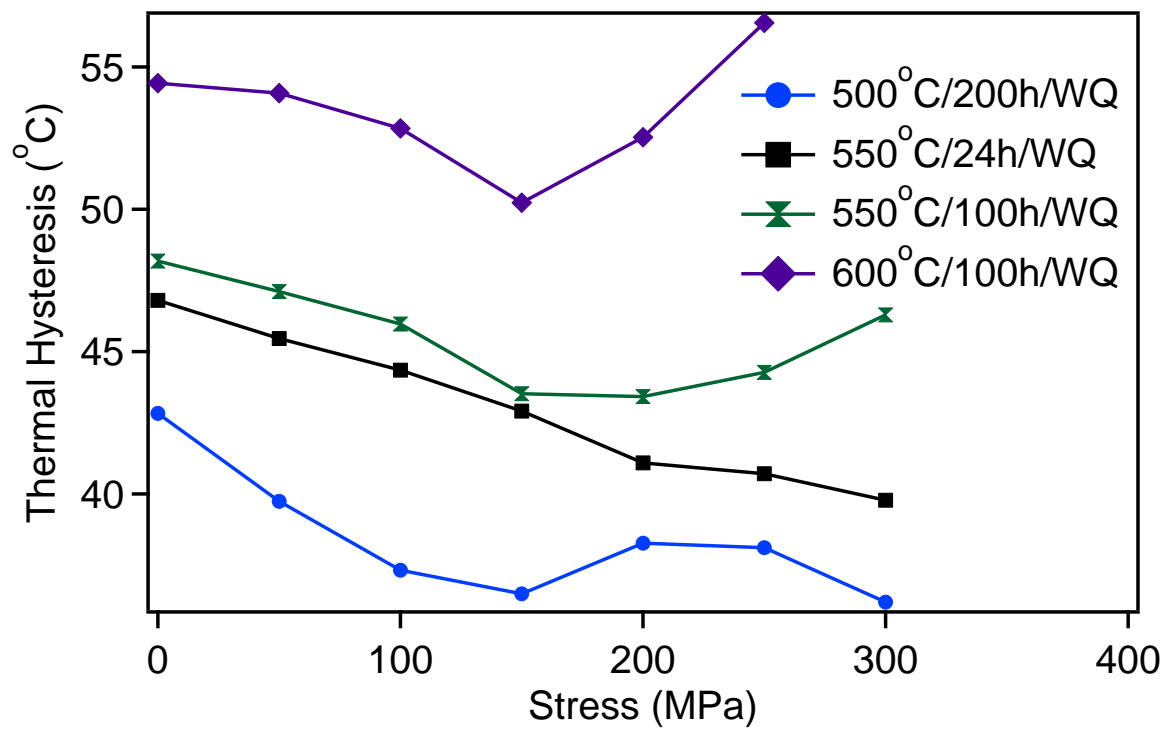

Figure 9: Summary of the thermal hysteresis of aged $\mathrm{Ni}_{50.3} \mathrm{Ti}_{34.7} \mathrm{Zr}_{15}$ samples during thermal cycling in tension as a function of applied stress. 


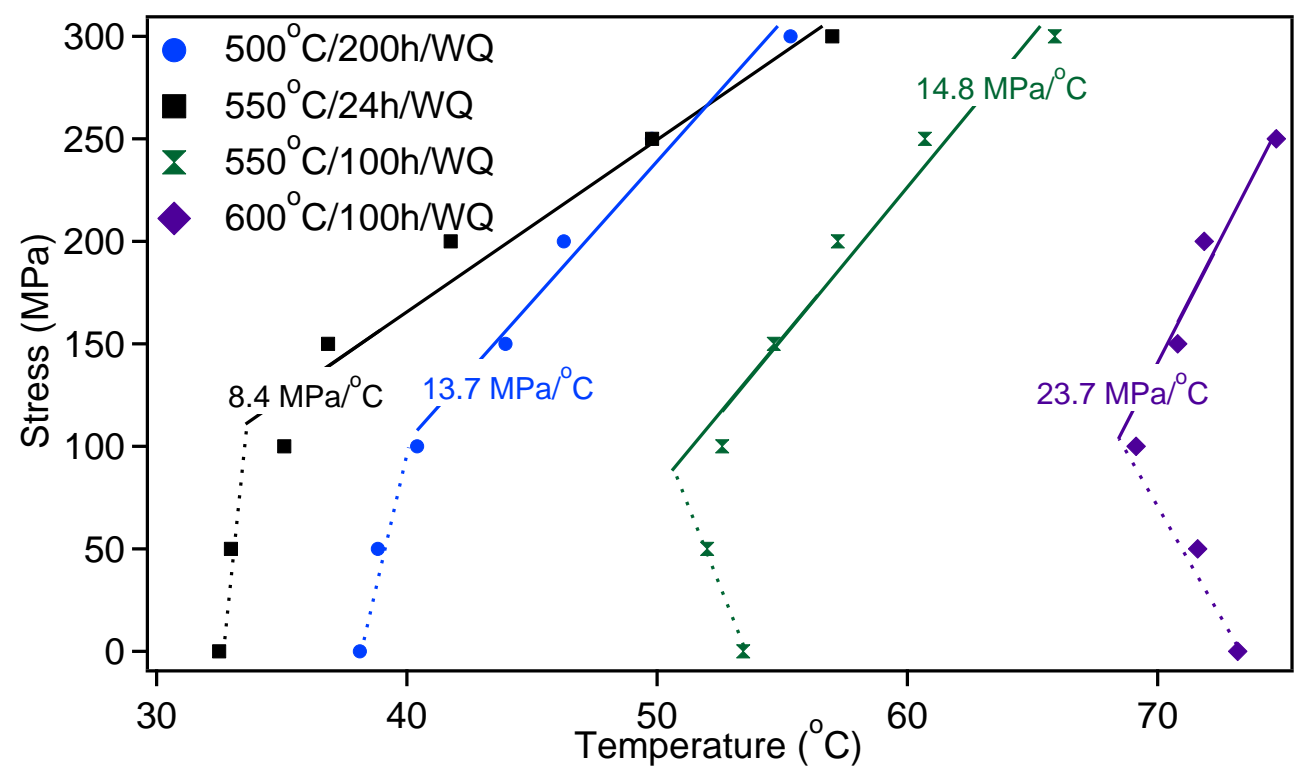

Figure 10: The stress vs. temperature relationships for the start of the martensitic transformation, $M_{s}$, for aged $\mathrm{Ni}_{50.3} \mathrm{Ti}_{34.7} \mathrm{Zr}_{15}$ samples during thermal cycling in tension. 


\section{TABLES}

Table 1

Composition of the present $\mathrm{Ni}_{50.3} \mathrm{Ti}_{34.7} \mathrm{Zr}_{15} \mathrm{SMA}$ after solution heat treatment at $900{ }^{\circ} \mathrm{C}$ for $1 \mathrm{~h}$, measured using WDS. \pm indicates the standard deviation from a total of 10 measurements over the specimens.

\begin{tabular}{llll}
\hline & Ni (at.\%) & Ti (at.\%) & Zr (at.\%) \\
\hline Measured & $50.37 \pm 0.10$ & $34.75 \pm 0.07$ & $14.88 \pm 0.14$ \\
Nominal & 50.3 & 34.7 & 15.0 \\
\hline
\end{tabular}

